\title{
Explaining Exchange Rate Anomalies in a Model with Taylor-rule Fundamentals and Consistent Expectations
}

\author{
Kevin J. Lansing \\ Federal Reserve Bank of San Francisco \\ Jun Ma \\ University of Alabama
}

June 2016

Working Paper 2014-22

http://www.frbsf.org/economic-research/publications/working-papers/wp2014-22.pdf

\section{Suggested citation:}

Lansing, Kevin J., Jun Ma. 2016. "Explaining Exchange Rate Anomalies in a Model with Taylor-rule Fundamentals and Consistent Expectations.” Federal Reserve Bank of San Francisco Working Paper 2014-22. http://www.frbsf.org/economicresearch/publications/working-papers/wp2014-22.pdf

The views in this paper are solely the responsibility of the authors and should not be interpreted as reflecting the views of the Federal Reserve Bank of San Francisco or the Board of Governors of the Federal Reserve System. 


\title{
Explaining Exchange Rate Anomalies in a Model with Taylor-rule Fundamentals and Consistent Expectations
}

June 27, 2016

\begin{abstract}
We introduce boundedly-rational expectations into a standard asset-pricing model of the exchange rate, where cross-country interest rate differentials are governed by Taylortype rules. Agents augment a lagged-information random walk forecast with a term that captures news about Taylor-rule fundamentals. The coefficient on fundamental news is pinned down using the moments of observable data such that the resulting forecast errors are close to white noise. The model generates volatility and persistence that is remarkably similar to that observed in monthly exchange rate data for Canada, Japan, and the U.K. Regressions performed on model-generated data can deliver the well-documented forward premium anomaly.
\end{abstract}

Keywords: Exchange rates, Uncovered interest rate parity, Forward premium anomaly, Random-walk expectations, Excess volatility.

JEL Classification: D83, D84, E44, F31, G17. 


\section{Introduction}

This paper develops a simple framework that can reproduce numerous quantitative features of real-world exchange rates. The key aspect of our approach is the way in which agents' expectations are modeled. Starting from a standard asset-pricing model of the exchange rate, we postulate that agents augment a lagged-information random walk forecast with news about fundamentals. Fundamentals in our model are determined by cross-country interest rate differentials which, in turn, are described by Taylor-type rules, along the lines of Engel and West $(2005,2006)$. We solve for a "consistent expectations equilibrium," in which the coefficient on fundamental news in the agent's subjective forecast rule is pinned down using the observed covariance between exchange rate changes and fundamental news. This learnable equilibrium delivers the result that the forecast errors observed by an agent are close to white noise, making it difficult to detect any misspecification of the subjective forecast rule. ${ }^{1}$

We demonstrate that our consistent expectations model can generate volatility and persistence that is remarkably similar to that observed in monthly bilateral exchange rate data (relative to the U.S.) for Canada, Japan, and the U.K. over the period 1974 to 2012. We show that regressions performed on model-generated data can deliver the so-called "forwardpremium anomaly," whereby a high interest rate currency tends to appreciate, thus violating the uncovered interest parity (UIP) condition. Moreover, the estimated slope coefficient in the model UIP regressions can vary over a wide range when estimated using a rolling sample period. This result is consistent with the wide range of coefficient estimates observed across countries and time periods in the data. ${ }^{2}$

In our model, agents' perceived law of motion (PLM) for the exchange rate is a driftless random walk that is modified to include an additional term involving fundamental news, i.e., the innovation to the $\operatorname{AR}(1)$ driving process that is implied by the Taylor-rule based interest rate differential. The standard asset-pricing model implies that the contemporaneous realization of the exchange rate at time $t$ depends in part on agents' subjective forecast of the exchange rate at time $t+1$. Following the methodology of the adaptive learning literature, we postulate that when constructing their subjective forecast, agents employ the lagged realization of the exchange rate at time $t-1$. Use of the lagged realization ensures that the forecast is "operational." Since the contemporaneous realization depends on the forecast, it is not clear how agents could make use of this realization when constructing their forecast in real-time. Our setup captures an idea originally put forth in an informal way by Froot and Thaler (1990), who suggested that the empirical failure of the UIP condition might be linked to the fact that

\footnotetext{
${ }^{1}$ The equilibrium concept that we employ was originally put forth by Hommes and Sorger (1998). A closelyrelated concept is the "restricted perceptions equilibrium" described by Evans and Honkopohja (2001, Chapter 13). For other applications of consistent expectations to asset pricing or inflation, see Sögner and Mitlöhner (2002), Branch and McGough (2005), Evans and Ramey (2006), Lansing (2009, 2010), and Hommes and Zhu (2014).

${ }^{2}$ For evidence of variability in estimated UIP slope coefficients, see Bansal (1997), Flood and Rose (2002), Baillie and Chang (2011), Baillie and Cho (2014), and Ding and Ma (2013).
} 
investors "may need some time to think about trades before executing them, or that they simply cannot respond quickly to recent information."

We assume that enough time has gone by for agents to have discovered the parameters governing the law of motion for the fundamental driving variable, thus allowing them to infer the fundamental innovation, i.e., news. Given the time series of past data, agents' can estimate the coefficient on fundamental news in their PLM by running a simple regression. The agents' forecast rule can be viewed as boundedly-rational because the resulting actual law of motion (ALM) for the exchange rate exhibits a near-unit root with innovations that depend on Taylor-rule fundamentals. ${ }^{3}$

We show that regardless of the starting value for the coefficient on fundamental news in the subjective forecast rule, a standard real-time learning algorithm will converge to the vicinity of the fixed point which defines the unique consistent expectations (CE) equilibrium. Use of the lagged exchange rate in the subjective forecast rule is the crucial element needed to generate the forward-premium anomaly. In equilibrium, the CE model delivers substantial "excess volatility" of the exchange rate relative to the rational expectations (RE) version of the model. Indeed, the CE model's prediction for the volatility of exchange rate changes is very close to that observed in the data.

Our setup is motivated by two important features of the data: (1) real-world exchange rates exhibit near-random walk behavior, and (2) exchange rates and fundamentals do exhibit some tenuous empirical links. Andersen et al. (2003) employ high frequency data to show that fundamental macroeconomic news surprises induce shifts in the exchange rate. Survey responses from professional exchange rate forecasters indicate that the vast majority use fundamental economic data to help construct their forecasts (Dick and Menkhoff 2013; Ter Ellen et al. 2013).

When we apply the CE model's forecast rule to exchange rate data for Canada, Japan, and the U.K., we find that the inclusion of fundamental news together with the lagged exchange rate helps to improve forecast accuracy relative to an otherwise similar random walk forecast that omits the fundamental news term. Moreover, once the fundamental news term is included in the forecasting regression, forecast performance is often improved by using the lagged exchange rate rather than the contemporaneous exchange rate.

Using survey data of financial institutions for 3-month ahead forecasts of exchange rates, we show that changes in the interest rate differential (a proxy for fundamental news) are helpful in explaining movements in the survey forecasts - a result that is consistent with the subjective forecast rule in the CE model. In particular, the data show that survey respondents tend to forecast a currency appreciation during periods when the change of interest rate differential is positive.

\footnotetext{
${ }^{3}$ Lansing (2010) employs a similar random walk plus fundamentals subjective forecast rule in a standard Lucas-type asset pricing model to account for numerous quantitative features of long-run U.S. stock market data.
} 


\subsection{Related Literature}

Efforts to explain movements in exchange rates as a rational response to economic fundamentals have, for the most part, met with little success. More than thirty years ago, Meese and Rogoff (1983) demonstrated that none of the usual economic variables (money supplies, real incomes, trade balances, inflation rates, interest rates, etc.) could help forecast future exchange rates better than a simple random walk forecast. With three decades of additional data in hand, researchers continue to confirm the Meese-Rogoff results. ${ }^{4}$ While some tenuous links between fundamentals and exchange rates have been detected, the empirical relationships are generally unstable (Bacchetta and Van Wincoop 2004, 2013), hold only at 5 to 10 year horizons (Chinn 2006), or operate in the wrong direction, i.e., exchange rates may help predict fundamentals but not vice versa (Engel and West 2005). ${ }^{5}$ The failure of traditional fundamental variables to improve forecasts of future exchange rates has been called the "exchange rate disconnect puzzle."

Another puzzle relates to the "excess volatility" of exchange rates. Like stock prices, exchange rates appear to move too much when compared to changes in observable fundamentals. ${ }^{6}$ Engel and West (2006) show that a standard rational expectations model can match the observed persistence of real-world exchange rates, but it substantially underpredicts the observed volatility. West (1987) makes the point that exchange rate volatility can be reconciled with fundamental exchange rate models if one allows for "regression disturbances," i.e., exogenous shocks that can be interpreted as capturing shifts in unobserved fundamentals. Similarly, Balke et al. (2013) find that unobserved factors (labeled "money demand shifters") account for most of the volatility in the U.K./U.S. exchange rate using data that extends back more than a century. An innovative study by Bartolini and Gioginianni (2001) seeks to account for the influence of unobserved fundamentals using survey data on exchange rate expectations. The study finds "broad evidence...of excess volatility with respect to the predictions of the canonical asset-pricing model of the exchange rate with rational expectations" (p. 518).

A third exchange rate puzzle is the so-called "forward-premium anomaly." In theory, a currency traded at a premium in the forward market predicts a subsequent appreciation of that currency in the spot market. In practice, there is a close empirical link between the observed forward premium and cross-country interest rate differentials, consistent with the covered interest parity condition. Hence, theory predicts that a low interest rate currency should, on average, appreciate relative to a high interest rate currency because the subsequent appreciation compensates investors for the opportunity cost of holding a low interest rate

\footnotetext{
${ }^{4}$ The Meese-Rogoff results are very robust; they show that realized future fundamentals also fail to forecast future exchange rates. For surveys of this vast literature, see Rossi (2013), Cheung, Chinn and Pascual (2005), and Sarno (2005).

${ }^{5}$ Specifically, Engel and West (2005) find Granger causality running from exchange rates to fundamentals. Recently, however, Ko and Ogaki (2015) demonstrate that this result is not robust after correcting for the small-sample size.

${ }^{6}$ Early studies applied to exchange rate volatility include Huang (1981) and Wadhwani (1987).
} 
bond. The theoretical slope coefficient from a regression of the observed exchange rate change on the prior interest rate differential is exactly equal to one. This prediction of the theory, known as the uncovered interest parity condition, is grossly violated in the data. Regressions of the observed exchange rate change on the prior interest rate differential yield estimated slope coefficients that are typically negative and significantly different from one (Fama 1984). Like the other two puzzles, the forward-premium anomaly has stood the test of time. ${ }^{7}$

The wrong sign of the slope coefficient in UIP regressions can be reconciled with noarbitrage and rational expectations if investors demand a particular type of risk premium to compensate for holding an uncovered currency position. By failing to account for a potentially time-varying risk premium that may co-move with the interest rate differential, the standard UIP regression may deliver a biased estimate of the slope coefficient. ${ }^{8}$ Lustig and Verdelhan (2007) provide some evidence that carry-trade profits (excess returns from betting against UIP) may reflect a compensation for risk that stems from a negative correlation between the carrytrade profits and investors' consumption-based marginal utility. ${ }^{9}$ However, Burnside (2011) points out that their empirical model is subject to weak identification such that there is no concrete evidence for the postulated connection between carry-trade profits and fundamental risk. Moreover, Burnside et al. (2011) show that there is no statistically significant covariance between carry-trade profits and conventional risk factors.

Verdelhan (2010) develops a rational model with time-varying risk premiums along the lines of Campbell and Cochrane (1999). The model implies that rational domestic investors will expect low future returns on risky foreign bonds in good times (due to an expected appreciation of the domestic currency) when risk premia are low and domestic interest rates are high relative to foreign interest rates. Hence, the model delivers the prediction that the domestic currency will appreciate, on average, when domestic interest rates are high - thus violating the UIP condition, as in the data. Unfortunately, the idea that investors expect low future returns in good times is strongly contradicted by a wide variety of survey evidence. The survey evidence shows that investors typically expect high future returns in good times, as they extrapolate from past return data. ${ }^{10}$ Overall, the survey evidence tells us that rationally time-varying risk premiums are not a convincing explanation for the empirical failure of UIP.

Our approach relates to some previous literature that has employed models with distorted beliefs to account for the behavior of exchange rates. Gourinchas and Tornell (2004) postulate that agents have distorted beliefs about the law of motion for fundamentals. Related mechanisms are proposed by Burnside et al. (2011), Ilut (2012), and Yu (2013). In contrast, we postulate that agents have distorted beliefs about the law of motion for exchange rates, not

\footnotetext{
${ }^{7}$ For recent evidence, see Baillie and Chang (2011) and Baillie and Cho (2014).

${ }^{8}$ See Engel (1996) for a survey of this large literature and Engel (2014) for a review of new developments in this field.

${ }^{9}$ See also Lustig et al. (2014).

${ }^{10}$ For additional details, see Amromin and Sharpe (2014), Greenwood and Shleifer (2014), and Koijen et al. (2015).
} 

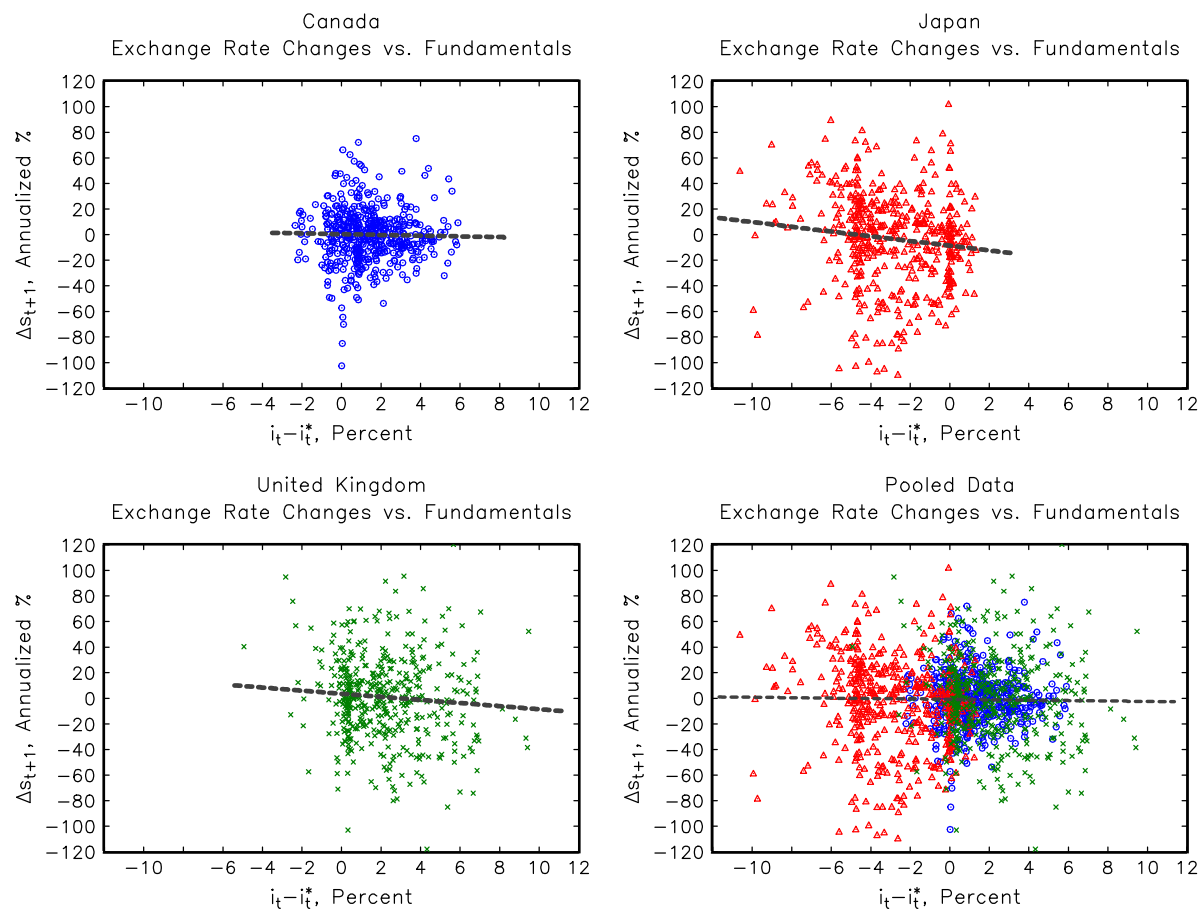

Figure 1: There is no tight systematic relationship between monthly exchange rate changes and the prior month's interest rate differential (exchange rate disconnect puzzle). The slope of the fitted relationship between the observed exchange rate change and the prior month's interest rate differential is negative (forward-premium anomaly).

fundamentals.

Bacchetta and Van Wincoop (2007) introduce "random walk expectations" into an exchange rate model with risk aversion and infrequent portfolio adjustments. Unlike our setup, the agent's subjective forecast in their model completely ignores fundamentals. While their model can account for the forward-premium anomaly, it relies on exogenous shocks from ad hoc noise traders to account for the observed volatility of exchange rate changes.

Chakraborty and Evans (2008) introduce constant-gain learning about the reduced-form law of motion for the exchange rate. The agent in their model employs the correct (i.e., rational) form for the law of motion, but the estimated parameters are perpetually updated using recent data. They show that statistical variation in the estimated parameters may cause the UIP condition to be violated, particularly in small samples. However, their model does not account for excess volatility of the exchange rate. Mark (2009) develops a model with perpetual learning about the Taylor-rule coefficients that govern the cross-country interest rate differential. He shows that the model can account for major swings in the real deutschemark/euro-dollar exchange rate over the period 1976 to 2007. 

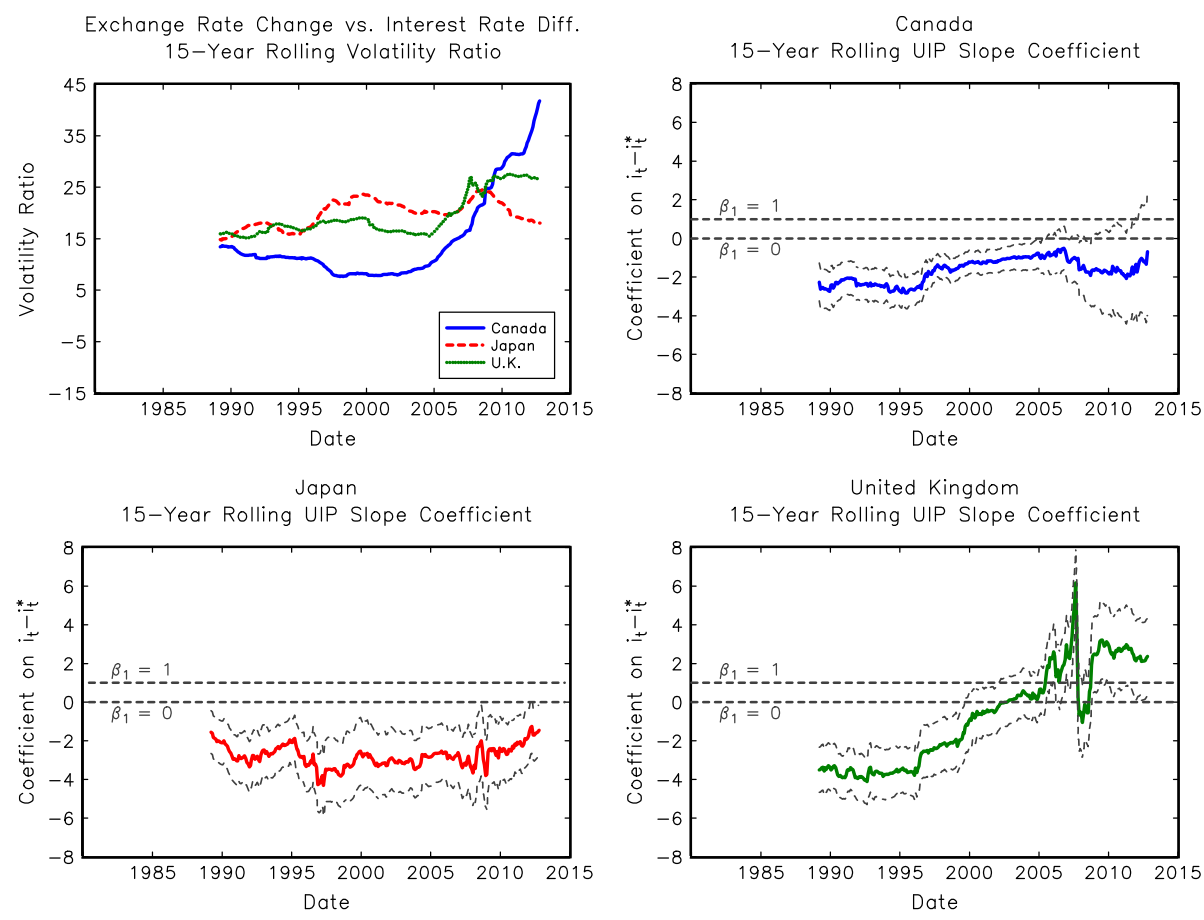

Figure 2: The volatility of the exchange rate change is 10 to 40 times higher than the volatility of the cross-country interest rate differential (excess volatility puzzle). Estimated UIP slope coefficients lie mostly in negative territory and exhibit substantial time variation.

\section{Exchange Rate Anomalies}

According to UIP theory, the cross-country interest rate differential should be a key explanatory variable for subsequent exchange rate changes. Figure 1 plots scatter diagrams of monthly bilateral exchange rate changes (in annualized percent) versus the prior month's average short-term nominal interest rate differential (in percent) for three pairs of countries, namely, Canada/U.S., Japan/U.S. and U.K./U.S. The data covers the period from January 1974 through October 2012. ${ }^{11}$ The bottom right panel of Figure 1 shows a scatter diagram of the pooled data.

Figure 1 shows that there is no tight systematic relationship between monthly exchange rate changes and the prior month's interest rate differential (exchange rate disconnect puzzle). The dashed regression lines in Figure 1 show a negative slope in the fitted relationship between the observed exchange rate change and the prior month's interest rate differential (forwardpremium anomaly). The top left panel of Figure 2 plots the relative volatility of exchange rate changes to interest rate differentials, where volatilities are computed as the standard deviation

\footnotetext{
${ }^{11}$ Exchange rate changes are computed as the log difference of sequential end-of-month values and then annualized. Interest rates are annualized 3-month government bond yields. All data are from the IMF's International Financial Statistics database.
} 
over a 15-year (180-month) rolling sample period. The volatility of exchange rate changes is 10 to 40 times higher than the volatility of the interest rate differential (excess volatility puzzle).

The remaining panels of Figure 2 plot the estimated slope coefficients $\beta_{1}$ (with standard error bands) from 15-year rolling regressions that take the form:

$$
\Delta s_{t+1}=\beta_{0}+\beta_{1}\left(i_{t}-i_{t}^{*}\right)+\varepsilon_{t+1},
$$

where $s_{t} \equiv \log \left(S_{t}\right)$ is the logarithm of the nominal exchange rate (home currency per US dollar) and $\Delta s_{t+1} \equiv s_{t+1}-s_{t}$ is the monthly percent change (annualized) from period $t$ to $t+1$. The short-term nominal interest rate differential is $i_{t}-i_{t}^{*}$, where $i_{t}$ is the rate for either Canada, Japan, or the U.K. and $i_{t}^{*}$ is the U.S. interest rate. Under UIP (which assumes rational expectations and risk-neutral investors), the no-arbitrage condition is $E_{t} \Delta s_{t+1}=i_{t}-i_{t}^{*}$. Hence, UIP would imply $\beta_{0}=0$ and $\beta_{1}=1$, with the residual $\varepsilon_{t+1}$ reflecting white-noise rational forecast errors.

For all three countries, the rolling estimates of $\beta_{1}$ lie mostly in negative territory, thus violating the UIP condition. Table 1 provides the full-sample estimates for $\beta_{1}$. The point estimates are all negative, consistent with dashed regression lines shown in Figure 1. Moreover, the 95 percent confidence intervals based on the reported standard errors exclude the theoretical prediction of $\beta_{1}=1$ in their coverages. ${ }^{12}$

Table 1. Full-Sample UIP Slope Coefficients

\begin{tabular}{ccccc}
\hline \hline & & & & Pooled \\
& Canada & Japan & U.K. & Data \\
\cline { 2 - 5 }$\hat{\beta}_{1}$ & -0.29 & -1.86 & -1.21 & -0.16 \\
Std. Error & $(0.65)$ & $(0.75)$ & $(0.76)$ & $(0.29)$ \\
\hline
\end{tabular}

Note: Sample period is 1974.m1 to 2012.m10.

The consistently negative estimates for $\beta_{1}$ reported here and elsewhere in the literature have interesting economic implications. In practice, the results imply that a carry-trade strategy (taking a long position in high-interest currency while shorting a low-interest currency) can deliver substantial excess returns, where excess returns are measured by $\left(i_{t}-i_{t}^{*}\right)-\Delta s_{t+1}$. When $\beta_{1}<1$, the future excess return can be predicted using the current interest rate differential $i_{t}-i_{t}^{*}$, which raises doubts about market efficiency. Efforts to account for the predictability of excess returns in the data can be classified into two main approaches: (i) linking excess returns to some form of compensation for bearing risk, or (ii) allowing for departures from fully-rational expectations. Empirical evidence using conventional risk factors argues against the first approach (Burnside et al. 2011). In this paper, we follow the second approach.

Another notable feature of the UIP regressions, evident in Figure 2, is the substantial time variation in the estimated slope coefficient for a given country. Baillie and Chang (2011) and

\footnotetext{
${ }^{12}$ Using a dataset of 23 countries for the sample period of the 1990s, Flood and Rose (2002) obtain positive estimated values of $\beta_{1}$ using pooled data. However, they acknowledge (p. 257) that "pooling is a dubious procedure" given the heterogeneity in the individual country estimates of $\beta_{1}$.
} 
Baillie and Cho (2014) employ time-varying parameter regressions to capture this feature of the data. Bansal (1997) shows that the sign of $\beta_{1}$ appears to be correlated with the sign of the interest rate differential, but his results do not generalize to other sample periods or countries. Ding and Ma (2013) develop a model of cross-border portfolio reallocation that can help explain a time-varying $\beta_{1}$ estimate. Our model can deliver a negative and statistically significant estimate of $\beta_{1}$ in long-sample regressions as well as substantial timevariation in the estimated slope coefficient in rolling regressions. The time variation in the estimated slope coefficient arises for two reasons: (i) the actual law of motion that governs $\Delta s_{t+1}$ in the consistent expectations equilibrium turns out to differ in significant ways from the UIP regression equation (1), and (ii) the volatility of $\Delta s_{t+1}$ in the consistent expectations equilibrium is much higher than the volatility of $i_{t}-i_{t}^{*}$.

\section{Model}

The framework for our analysis is a standard asset-pricing model of the exchange rate. Fundamentals are given by cross-country interest rate differentials which, in turn, are described by Taylor-type rules. Given our data, the home country in the model represents either Canada, Japan, or the U.K. while the foreign country represents the United States (denoted by * variables).

We postulate that the home country central bank sets the short-term nominal interest rate according to the following Taylor-type rule

$$
i_{t}=\theta i_{t-1}+(1-\theta)\left\{g_{\pi} \pi_{t}+g_{y} y_{t}+g_{s}\left[s_{t}-\kappa s_{t-1}-(1-\kappa) \bar{s}_{t}\right]\right\}+\eta_{t},
$$

where $i_{t}$ is the short term nominal interest rate, $\pi_{t}$ is the inflation rate (log difference of the price level over the past 12 months), $y_{t}$ is the output gap (log deviation of actual output from potential output), $s_{t}$ is the log of the nominal exchange rate (home currency per U.S. dollar), $s_{t-1}$ is the lagged exchange rate, and $\bar{s}_{t} \equiv p_{t}-p_{t}^{*}$ is a benchmark exchange rate implied by the purchasing power parity (PPP) condition, where $p_{t}$ is the domestic price level and $p_{t}^{*}$ is the foreign price level. ${ }^{13}$ When $\kappa=0$, the central bank reacts to $s_{t}-\bar{s}_{t}$ which is the deviation of the exchange rate from the PPP benchmark, consistent with the models employed by Engel and West $(2005,2006)$. When $\kappa=1$, the central bank reacts to the exchange rate change $\Delta s_{t}=s_{t}-s_{t-1}$, consistent with the empirical policy rule estimates of Lubik and Schorfheide (2007) and Justiniano and Preston (2010) for a variety of industrial countries. Motivated by the empirical evidence, we set $\kappa \simeq 1 .{ }^{14}$ The term $\eta_{t}$ represents an exogenous monetary policy shock. In contrast to Engel and West $(2005,2006)$, we allow for interest-rate smoothing on the part of the central bank, as governed by the parameter $\theta>0$. For the remaining reaction

\footnotetext{
${ }^{13}$ We omit constant terms from equation (2) because our empirical application of the central bank reaction function makes use of demeaned data.

${ }^{14}$ As noted below, we impose the parameter restriction $0 \leq \kappa<1$ to ensure the existence of a unique rational expectations solution of the model.
} 
function parameters, we follow standard practice in assuming $g_{\pi}>1$, and $g_{y}, g_{s}>0$. In other words, the central bank responds more than one-for-one to movements in inflation and raises the nominal interest rate in response to a larger output gap or a depreciating home currency $\left(\Delta s_{t}>0\right)$.

The foreign (i.e., U.S.) central bank sets the short-term nominal interest rate according to

$$
i_{t}^{*}=\theta i_{t-1}^{*}+(1-\theta)\left[g_{\pi} \pi_{t}^{*}+g_{y} y_{t}^{*}\right]+\eta_{t}^{*},
$$

where we assume that the reaction function parameters $\theta, g_{\pi}$, and $g_{y}$ are the same across countries. ${ }^{15}$ Subtracting equation (3) from equation (2) yields the following expression for the cross-country interest rate differential

$$
\begin{aligned}
i_{t}-i_{t}^{*}= & \theta\left(i_{t-1}-i_{t-1}^{*}\right)+(1-\theta)\left\{g_{\pi}\left(\pi_{t}-\pi_{t}^{*}\right)+g_{y}\left(y_{t}-y_{t}^{*}\right)+g_{s}\left[s_{t}-\kappa s_{t-1}-(1-\kappa) \bar{s}_{t}\right]\right\} \\
& +\eta_{t}-\eta_{t}^{*} .
\end{aligned}
$$

Assuming risk-neutral, rational investors, the uncovered interest rate parity condition implies

$$
E_{t} s_{t+1}-s_{t}=i_{t}-i_{t}^{*}
$$

where $E_{t} s_{t+1}$ is the rational forecast of next period's log exchange rate. ${ }^{16}$ The UIP condition says that a negative interest rate differential $i_{t}-i_{t}^{*}<0$ will exist when rational investors expect a home currency appreciation, i.e., when $E_{t} s_{t+1}<s_{t}$. The expected appreciation compensates investors for the opportunity cost of holding a low interest rate domestic bond rather than a high interest rate foreign bond. Rational expectations implies $E_{t} s_{t+1}=s_{t+1}-\varepsilon_{t+1}$, where $\varepsilon_{t+1}$ is a white-noise forecast error. Hence, theory predicts that, on average, a low interest rate currency should appreciate relative to a high interest rate currency such that $E\left(s_{t+1}-s_{t}\right)<0$.

Substituting the cross-country interest rate differential (4) into the UIP condition (5) and solving for $s_{t}$ yields the following no-arbitrage condition that determines the equilibrium exchange rate

$$
s_{t}=b E_{t} s_{t+1}+\kappa(1-b) s_{t-1}+x_{t}, \quad b \equiv \frac{1}{1+(1-\theta) g_{s}}<1,
$$

where $b$ is the effective discount factor and $x_{t}$ is the fundamental driving variable defined as

$$
x_{t} \equiv-b \theta\left(i_{t-1}-i_{t-1}^{*}\right)-b(1-\theta)\left[g_{\pi}\left(\pi_{t}-\pi_{t}^{*}\right)+g_{y}\left(y_{t}-y_{t}^{*}\right)-g_{s}(1-\kappa)\left(p_{t}-p_{t}^{*}\right)\right]-b\left(\eta_{t}-\eta_{t}^{*}\right),
$$

where we have made the substitution $\bar{s}_{t}=p_{t}-p_{t}^{*} \cdot{ }^{17}$

\footnotetext{
${ }^{15}$ Consistent with the literature (see for example Engel and West 2005) we assume that the U.S. policy interest rate does not react to the exchange rate. For convenience, we assume that the remaining policy rule parameters are the same across countries. A departure from either of these assumptions would not alter the model or the quantitative results in a substantial way. See footnote 17 for further clarification.

${ }^{16}$ More precisely, the UIP condition is $E_{t} S_{t+1} / S_{t}=\left(1+i_{t}\right) /\left(1+i_{t}^{*}\right)$. Following standard practice, we take $\operatorname{logs}$ of both sides and ignore the Jensen's inequality term such that $\log \left(E_{t} S_{t+1}\right) \simeq E_{t} \log \left(S_{t+1}\right)$.

${ }^{17}$ The basic form of equations (6) and (7) will remain unchanged if we assume that the foreign central bank also reacts to the exchange rate, but with a smaller reaction coefficient $g_{s}^{*}<g_{s}$. In this case, the effective discount factor becomes $b=1 /\left[1+(1-\theta)\left(g_{s}-g_{s}^{*}\right)\right]$.
} 
The no-arbitrage condition (6) shows that the equilibrium exchange rate $s_{t}$ depends on the agent's conditional forecast $E_{t} s_{t+1}$, the lagged exchange rate $s_{t-1}$, and the fundamental driving variable $x_{t}$. When $0 \leq \kappa<1$, the sum of the coefficients on $E_{t} s_{t+1}$ and $s_{t-1}$ is less than one which ensures the existence of a unique rational expectations solution. The general form of equation (6), whereby the current value of an endogenous variable depends on its own expected future value, its lagged value, and a driving variable appears in a wide variety of economic models, such as the hybrid New Keynesian Phillips Curve (Galí, et al. 2005).

The macroeconomic variables that enter the definition of $x_{t}$ exhibit a high degree of persistence in the data. We therefore model the behavior of the fundamental driving variable using the following stationary $\mathrm{AR}(1)$ process

$$
x_{t}=\rho x_{t-1}+u_{t}, \quad u_{t} \sim N\left(0, \sigma_{u}^{2}\right), \quad|\rho|<1,
$$

where the parameter $\rho$ governs the degree of persistence. While some studies allow for a unit root in the law of motion for fundamentals, we maintain the assumption of stationarity for consistency with most of the literature. In a finite data sample, it is nearly impossible to distinguish between a unit root process and one that is stationary but highly persistent (Cochrane 1991).

Given values for $x_{t}$ and $s_{t}$, we can recover the current-period interest rate differential as follows

$$
i_{t}-i_{t}^{*}=-\frac{1}{b} x_{t}+\left(\frac{1-b}{b}\right)\left(s_{t}-\kappa s_{t-1}\right) .
$$

Empirical estimates of central bank policy rules typically imply $\theta$ values in the range of 0.8 to 0.9 together with small values for $g_{s}$ such that $b \simeq 1$. In this case, the equilibrium dynamics for $i_{t}-i_{t}^{*}$ will be very similar to the equilibrium dynamics for $-x_{t}$. We will make use of this inverse relationship between the interest rate differential and the fundamental driving variable in our discussion of the results.

Our description of monetary policy in terms of Taylor-type interest rate rules has solid empirical support using data for many countries from the 1980's onwards (Lubik and Schorfheide 2007, Justiniano and Preston 2010). But even for earlier sample periods when Taylor-type rules may not have been followed, there would still exist a general feedback mechanism that implies some type of monetary policy response (e.g., a shift in the money growth rate) to movements in the exchange rate in order to help stabilize the macro-economy. For example, given a specification for money demand, a shift of the money growth rate in response to a movement in the exchange rate could be mapped to a corresponding shift in the interest rate differential. The Taylor-type interest rate rules (2) and (3) capture the idea of feedback mechanism from exchange rates to monetary policy in a tractable way, allowing us to compare the predictions of our consistent expectations model to an otherwise similar model with fully-rational expectations. 


\subsection{Rational Expectations}

Proposition 1 shows that the no-arbitrage condition (6) exhibits a unique rational expectation solution.

Proposition 1. When fundamentals are governed by equation (8), there is a unique solution to the no-arbitrage condition (6) under rational expectations (RE), as given by

$$
\begin{aligned}
s_{t} & =a_{s} s_{t-1}+a_{x} x_{t}, \\
a_{s} & =\frac{1-\sqrt{1-4 \kappa b(1-b)}}{2 b}, \quad a_{x}=\frac{1}{1-b\left(a_{s}+\rho\right)}
\end{aligned}
$$

Proof: See Appendix A.

Our parameter restriction $0 \leq \kappa<1$ implies the result $0 \leq a_{s}<(1-b) / b$. When $b \simeq 1$, the equilibrium coefficient on the lagged exchange rate must be a small positive number such that $a_{s} \simeq 0$. The result $0 \leq a_{s}<(1-b) / b$ further implies $(1-b \rho)^{-1}<a_{x}<[b(1-\rho)]^{-1}$. When $b$ and $\rho$ are both close to unity, the equilibrium coefficient $a_{x}$ will turn out to be a relatively large positive number. Since $a_{s} \simeq 0$, the equilibrium exchange rate approximately inherits the persistence properties of the fundamental driving variable $x_{t}$. Since $x_{t}$ is very persistent in the data, the RE model predicts a persistent exchange rate level. ${ }^{18}$ The unconditional moments for $s_{t}$ and $\Delta s_{t}$ implied by the RE model are contained in Appendix B.

Substituting the RE solution from Proposition 1 into the Taylor-rule based interest rate differential (9) yields the following expression for the equilibrium interest rate differential:

$$
\begin{aligned}
i_{t}-i_{t}^{*} & =-\frac{1}{b} x_{t}+\left(\frac{1-b}{b}\right) \underbrace{\left[\left(a_{s}-\kappa\right) s_{t-1}+a_{x} x_{t}\right]}_{s_{t}-\kappa s_{t-1}} \\
& =\frac{(1-b)\left(a_{s}-\kappa\right)}{b} s_{t-1}+\left(a_{s}+\rho-1\right) a_{x} x_{t} \\
& =\left(a_{s}-1\right) a_{s} s_{t-1}+\left(a_{s}-1\right) a_{x} x_{t}+a_{x} \rho x_{t} \\
& =\Delta s_{t+1}-a_{x} u_{t+1}
\end{aligned}
$$

where we have made use of the definition of $a_{x}$ in going from line 1 to line 2 , the definition of $a_{s}$ in going from line 2 to line 3 , and the laws of motion for $s_{t}$ and $x_{t}$ to obtain the result in line 4. Solving equation (10) for $\Delta s_{t+1}$ yields $\Delta s_{t+1}=\left(i_{t}-i_{t}^{*}\right)+a_{x} u_{t+1}$ which in turn implies the following slope coefficient from a UIP regression

$$
\beta_{1}=\frac{\operatorname{Cov}\left(\Delta s_{t+1}, i_{t}-i_{t}^{*}\right)}{\operatorname{Var}\left(i_{t}-i_{t}^{*}\right)}=\frac{\operatorname{Var}\left(i_{t}-i_{t}^{*}\right)}{\operatorname{Var}\left(i_{t}-i_{t}^{*}\right)}=1
$$

\footnotetext{
${ }^{18}$ For the baseline model calibration, the equilibrium coefficients turn out to be $a_{s}=0.0196$ and $a_{x}=20.23$.
} 


\subsection{Consistent Expectations}

Real-world exchange rates exhibit near-random walk behavior. A naive forecast rule that uses only the most recently-observed exchange rate almost always outperforms a fundamentalsbased forecast (Rossi 2013). In addition to its predictive accuracy, a random walk forecast has the advantage of economizing on computational and informational resources. As described many years ago by Nerlove (1983), "Purposeful economic agents have incentives to eliminate errors up to a point justified by the costs of obtaining the information necessary to do so...The most readily available and least costly information about the future value of a variable is its past value" (p. 1255).

Despite the dominance of a random walk forecast, survey evidence indicates that market participants continue to pay attention to fundamentals. A recent study by Dick and Menkhoff (2013) uses survey data to analyze the methods of nearly 400 professional exchange rate forecasters. The data shows that the vast majority of forecasters employ fundamental economic data together with past exchange rate movements to help construct their forecasts. Another study of survey data by Ter Ellen et al. (2014) finds evidence that large wholesale investors in the foreign exchange market employ fundamentals-based strategies as part of their forecasting toolkit.

To capture the above ideas, we postulate that agents' perceived law of motion (PLM) for the exchange rate is given by

$$
s_{t}=s_{t-1}+\alpha u_{t},
$$

where $u_{t}$ represents "fundamental news," as measured by the innovation to the $\mathrm{AR}(1)$ fundamental driving process (8). A long history of observations of $x_{t}$ would allow the agent to discover the law of motion for fundamentals and infer the value of $u_{t}$ from sequential observations of $x_{t}$ and $x_{t-1}$. Given the past data, agents could estimate the value of the parameter $\alpha$ by running a regression of $\Delta s_{t}$ on $u_{t}$. When $\alpha \neq 0$, the PLM implies that a fundamental news shock will induce an immediate jump in the exchange rate, consistent with the findings of Andersen et al. (2003) who employ high frequency data.

The PLM is used by agents to construct a subjective forecast $\widehat{E}_{t} s_{t+1}$ which takes the place of the rational forecast $E_{t} s_{t+1}$ in the no-arbitrage condition (6). Following Yu (2013), p. 476, our solution procedure assumes that the no-arbitrage condition "holds ex ante under investors' perception." ${ }^{19}$ But ex post, the exchange rate evolves according to the actual law of motion (ALM) to be derived below. Since the no-arbitrage condition implies that $s_{t}$ depends in part on the subjective forecast, it is not clear how an agent could make use of $s_{t}$ when constructing a forecast in real-time. Even in high frequency trading environments, investors who submit market orders to buy or sell an asset do not know the exact price at which their order will be filled. To deal with this timing issue, models that employ adaptive learning or other forms of boundedly-rational expectations typically assume that agents can only make

\footnotetext{
${ }^{19}$ This is also the setup in the distorted-belief models of Gourinchas and Tornell (2004) and Ilut (2012).
} 
use of the lagged realization of the forecast variable (in this case $s_{t-1}$ ) when constructing their subjective forecast at time $t .{ }^{20}$ According to the definition $(7), x_{t}$ does not not depend on $s_{t}$ so there is no controversy about including it in agents' information at time $t$.

Our lagged-information setup can be viewed as a reduced-form way of capturing various types of information frictions. The "sticky information" model of Mankiw and Reis (2002) postulates that only a fraction of agents update to the current vintage rational forecast each period. A "noisy information" model along the lines of Coibion and Gordonichencko (2015) implies that the current vintage rational forecast itself is a moving average of past observed values. Combining these two frictions could result in a very small weight assigned to the most recent data observation in the aggregate market forecast. Later, we show that forecast accuracy in the data can often be improved by using $s_{t-1}$ rather than $s_{t}$ in rolling forecast regressions that include a fundamental news term. ${ }^{21}$

Since the agent employs lagged information about the exchange rate, the PLM (12) is iterated ahead two periods to obtain their subjective forecast

$$
\begin{aligned}
\widehat{E}_{t} s_{t+1} & =\widehat{E}_{t}\left[s_{t}+\alpha u_{t+1}\right] \\
& =\widehat{E}_{t}\left[s_{t-1}+\alpha u_{t}+\alpha u_{t+1}\right] \\
& =s_{t-1}+\alpha u_{t}
\end{aligned}
$$

which makes use of the lagged exchange rate $s_{t-1}$, together with the contemporaneous fundamental news shock.

Substituting the agent's subjective forecast (13) into the no-arbitrage condition (6) and solving for $s_{t}$ yields the following actual law of motion for the exchange rate

$$
s_{t}=[1-(1-\kappa)(1-b)] s_{t-1}+b \alpha u_{t}+x_{t},
$$

where $x_{t}$ is governed by (8). Notice that the form of the ALM is similar, but not identical, to the RE model solution from Proposition 1. Recall that we previously showed that the equilibrium coefficient on the lagged exchange rate in the $\mathrm{RE}$ model must be a small positive number such that $a_{s} \simeq 0$. In the CE model, the parameter restriction $0 \leq \kappa<1$ implies that the equilibrium coefficient on the lagged exchange rate has a lower bound of $b$ when $\kappa=0$. This lower bound is close to unity when $b \simeq 1$. Since the equilibrium coefficient on $s_{t-1}$ in the CE model is near unity, the agents' perception of a unit root in the exchange rate turns out to be close to self-fulfilling. Hence we can say that agents are forecasting in a way that appears near-rational.

\footnotetext{
${ }^{20}$ For an overview of these methods, see Evans and Honkapohja (2001) and Hommes (2013).

${ }^{21}$ In an earlier version of the paper, we allowed a fraction $\lambda \in[0,1)$ of agents in the CE model to make use of contemporaneous information about the exchange rate, similar to the information setup in Adam et al. (2006). The quantitative results were broadly similar to those presented here.
} 


\subsubsection{Defining the Consistent Expectations Equilibrium}

We now define a "consistent expectations equilibrium" along the lines of Hommes and Sorger (1998) and Hommes and Zhu (2014). Specifically, the parameter $\alpha$ in the PLM (12) is pinned down using the moments of observable data. Since the PLM presumes that $s_{t}$ exhibits a unit root, agents inside the model can readily estimate $\alpha$ as follows

$$
\alpha=\frac{\operatorname{Cov}\left(\Delta s_{t}, u_{t}\right)}{\sigma_{u}^{2}}
$$

where $\operatorname{Cov}\left(\Delta s_{t}, u_{t}\right)$ and $\sigma_{u}^{2}$ can be computed from observable data. An analytical expression for the observable covariance can be derived from the ALM (14) which implies:

$$
\begin{aligned}
& \Delta s_{t}=-(1-\kappa)(1-b) s_{t-1}+b \alpha u_{t}+x_{t}, \\
& \operatorname{Cov}\left(\Delta s_{t}, u_{t}\right)=(b \alpha+1) \sigma_{u}^{2} .
\end{aligned}
$$

Equations (15) and (17) can be combined to form the following definition of equilibrium.

Definition 1. A consistent expectations (CE) equilibrium is defined as a perceived law of motion (12), a subjective forecast (13), an actual law of motion (14), and a subjective forecast parameter $\alpha$, such that the equilibrium value $\alpha^{*}$ is given by the unique fixed point of the linear map

$$
\begin{aligned}
\alpha & =T(\alpha) \equiv b \alpha+1, \\
\alpha^{*} & =\frac{1}{1-b},
\end{aligned}
$$

where $b \equiv 1 /\left[1+(1-\theta) g_{s}\right]<1$ is the effective discount factor.

The slope of the map $T(\alpha)$ determines whether the equilibrium is stable under learning. The slope is given by $T^{\prime}(\alpha)=b$. Since $0<T^{\prime}(\alpha)<1$, the CE equilibrium is globally stable. In Section 4, we demonstrate that a standard real-time learning algorithm always converges to the vicinity of the theoretical fixed point $\alpha^{*}$ regardless of the shock sequences or the starting value for $\alpha$.

\subsubsection{Implications for the Forward-Premium Anomaly}

The unconditional moments for $s_{t}$ and $\Delta s_{t}$ implied by the actual laws of motion (14) and (16) turn out to be quite complicated, as shown in Appendix C. It is useful to consider what happens to these moments when the effective discount factor approaches unity. When $b \rightarrow 1$ the equilibrium exchange rate exhibits a unit root. From equation (16), the actual law of 
motion becomes $\Delta s_{t}=\alpha u_{t}+x_{t}$ where $x_{t}=-\left(i_{t}-i_{t}^{*}\right)$ from equation (9). In this case, the analytical slope coefficient from a UIP regression is given by

$$
\beta_{1}=\lim _{b \rightarrow 1} \frac{\operatorname{Cov}\left(\Delta s_{t+1}, i_{t}-i_{t}^{*}\right)}{\operatorname{Var}\left(i_{t}-i_{t}^{*}\right)}=-\rho,
$$

which demonstrates that the CE model can deliver a negative slope coefficient, thus reproducing the well-documented forward-premium anomaly. When $0<b<1$, the slope coefficient remains negative, but is smaller in magnitude than in the limiting case of $b \rightarrow 1$. We will confirm these results numerically in the quantitative analysis presented in Section 4.

The intuition for the forward-premium anomaly in the CE model is not complicated. From equation (13), the subjective forecast is $\widehat{E}_{t} s_{t+1}=s_{t-1}+\alpha u_{t}$. Subtracting $s_{t}$ from both sides of this expression yields $\widehat{E}_{t} s_{t+1}-s_{t}=-\Delta s_{t}+\alpha u_{t}$. In contrast, the RE model implies $E_{t} s_{t+1}=s_{t+1}-\varepsilon_{t+1}$, where $\varepsilon_{t+1}$ is the white noise rational forecast error. Again subtracting $s_{t}$ from both sides yields $E_{t} s_{t+1}-s_{t}=\Delta s_{t+1}-\varepsilon_{t+1}$. The UIP condition (5) relates the forecasted change in the exchange rate to the prior interest rate differential $i_{t}-i_{t}^{*}$. By introducing positive weight on $s_{t-1}$ in the agent's forecast, the CE model shifts the temporal relationship between the forecasted change of the exchange rate and the interest rate differential, thus flipping the sign of the slope coefficient in the UIP regression.

Additional insight can obtained by substituting the ALM for $\Delta s_{t}$ (16) into the Taylorrule based interest rate differential (9) to obtain the following expression for the equilibrium interest rate differential:

$$
\begin{aligned}
i_{t}-i_{t}^{*} & =-\frac{1}{b} x_{t}+\left(\frac{1-b}{b}\right) \underbrace{\left\{[1-(1-\kappa)(1-b)-\kappa] s_{t-1}+b \alpha u_{t}+x_{t}\right\}}_{s_{t}-\kappa s_{t-1}}, \\
& =\left[(1-b)(1-\kappa) s_{t-1}+(1-b) \alpha u_{t}-x_{t}\right] \\
& =-\Delta s_{t}+\alpha u_{t},
\end{aligned}
$$

where the last expression again makes use of (16). From equation (1), the sign of the UIP slope coefficient $\beta_{1}$ is governed by the sign of $\operatorname{Cov}\left(\Delta s_{t+1}, i_{t}-i_{t}^{*}\right)$. Iterating equation (19) ahead one period and then solving for $\Delta s_{t+1}$ yields $\Delta s_{t+1}=-\left(i_{t+1}-i_{t+1}^{*}\right)+\alpha u_{t+1}$ which in turn implies

$$
\operatorname{Cov}\left(\Delta s_{t+1}, i_{t}-i_{t}^{*}\right)=-\operatorname{Cov}\left(i_{t+1}-i_{t+1}^{*}, i_{t}-i_{t}^{*}\right) .
$$

The right-side of the above expression will be negative so long as the interest rate differential exhibits positive serial correlation, as it does in both the model and the data. Intuitively, since the interest rate differential depends on the exchange rate via the Taylor-type rule, and the exchange rate depends on agents' expectations via the no-arbitrage condition (6), a departure from rational expectations that involves lagged information can shift the dynamics of the variables that appear on both sides of the UIP regression equation (1). 


\section{Quantitative Analysis}

\subsection{Numerical Solution for the Equilibrium}

Using the definition of the fundamental driving variable $x_{t}$ in equation (7), we construct time series for $x_{t}$ in Canada, Japan, and the U.K. using monthly data on the consumer price index, industrial production, and the short-term nominal interest rate differential relative to the U.S. The interest rate differential is computed using 3-month government bond yields. Our data are from the International Monetary Fund's International Financial Statistics (IFS) database and covers the period January 1974 through October 2012. To construct measures of the output gap for each country, we estimate and remove a quadratic trend from the logarithm of the industrial production index. ${ }^{22}$ In constructing the time series for $x_{t}$, we use the following calibrated values for the Taylor-rule parameters: $\theta=0.9, g_{\pi}=1.5, g_{y}=0.5, g_{s}=0.2$, and $\kappa=0.98$. These values are consistent with those typically employed or estimated in the literature. $^{23}$ Empirical estimates of the interest rate smoothing parameter typically imply $\theta \simeq 0.8$ for quarterly data. Since our model employs monthly data, we choose $\theta=0.9$. Given the Taylor-rule parameters, the effective discount factor in our model is $b \equiv 1 /\left[1+(1-\theta) g_{s}\right]=$ 0.9804 .

Table 2 reports summary statistics for the nominal interest rate differential (relative to the U.S.) and the constructed time series for $x_{t}$. As noted earlier in the discussion of equation (9), the equilibrium dynamics for $i_{t}-i_{t}^{*}$ are very similar to the equilibrium dynamics for $-x_{t}$ when $b \simeq 1$, as is the case here. For the model simulations, the parameters of the fundamental driving process (8) are chosen to achieve Std Dev $\left(x_{t}\right)=0.02$ (i.e., 2\%) and $\operatorname{Corr}\left(x_{t}, x_{t-2}\right) / \operatorname{Corr}\left(x_{t}, x_{t-1}\right)=0.95$, which are close to the values shown in Table 2 . This procedure yields $\sigma_{u}=0.00624$ and $\rho=0.95$.

Table 2. Summary Statistics of Data Fundamentals

\begin{tabular}{lccc}
\hline \hline & Canada & Japan & U.K. \\
\hline Std Dev $\left(i_{t}-i_{t}^{*}\right)$ & $1.62 \%$ & $2.35 \%$ & $2.18 \%$ \\
Std Dev $\left(x_{t}\right)$ & $1.64 \%$ & $2.52 \%$ & $2.30 \%$ \\
$\operatorname{Corr}\left(i_{t}-i_{t}^{*}, i_{t-1}-i_{t-1}^{*}\right)$ & 0.956 & 0.972 & 0.953 \\
$\operatorname{Corr}\left(i_{t}-i_{t}^{*},-x_{t}\right)$ & 0.964 & 0.957 & 0.955 \\
$\operatorname{Corr}\left(x_{t}, x_{t-2}\right) / \operatorname{Corr}\left(x_{t}, x_{t-1}\right)$ & 0.955 & 0.953 & 0.903 \\
\hline
\end{tabular}

Note: Sample period is from 1974.m1 to 2012.m10. The fundamental driving variable $x_{t}$ is defined by equation (7).

Figure 3 plots various theoretical moments of the CE model as we vary the PLM parameter $\alpha$ from 0 to 100 . Given the effective discount factor of $b=0.9804$, the equilibrium value is $\alpha^{*}=1 /(1-b)=51$. The top panels of Figure 3 plot the autocorrelation and standard

\footnotetext{
${ }^{22}$ Similar results are obtained if industrial production is detrended using the Hodrick-Prescott filter.

${ }^{23}$ See, for example, Lubik and Schorfheide (2007) and Justiniano and Preston (2010). In particular, they estimate values for the exchange rate response coefficient $g_{s}$ in the range of 0.07 to 0.29 .
} 

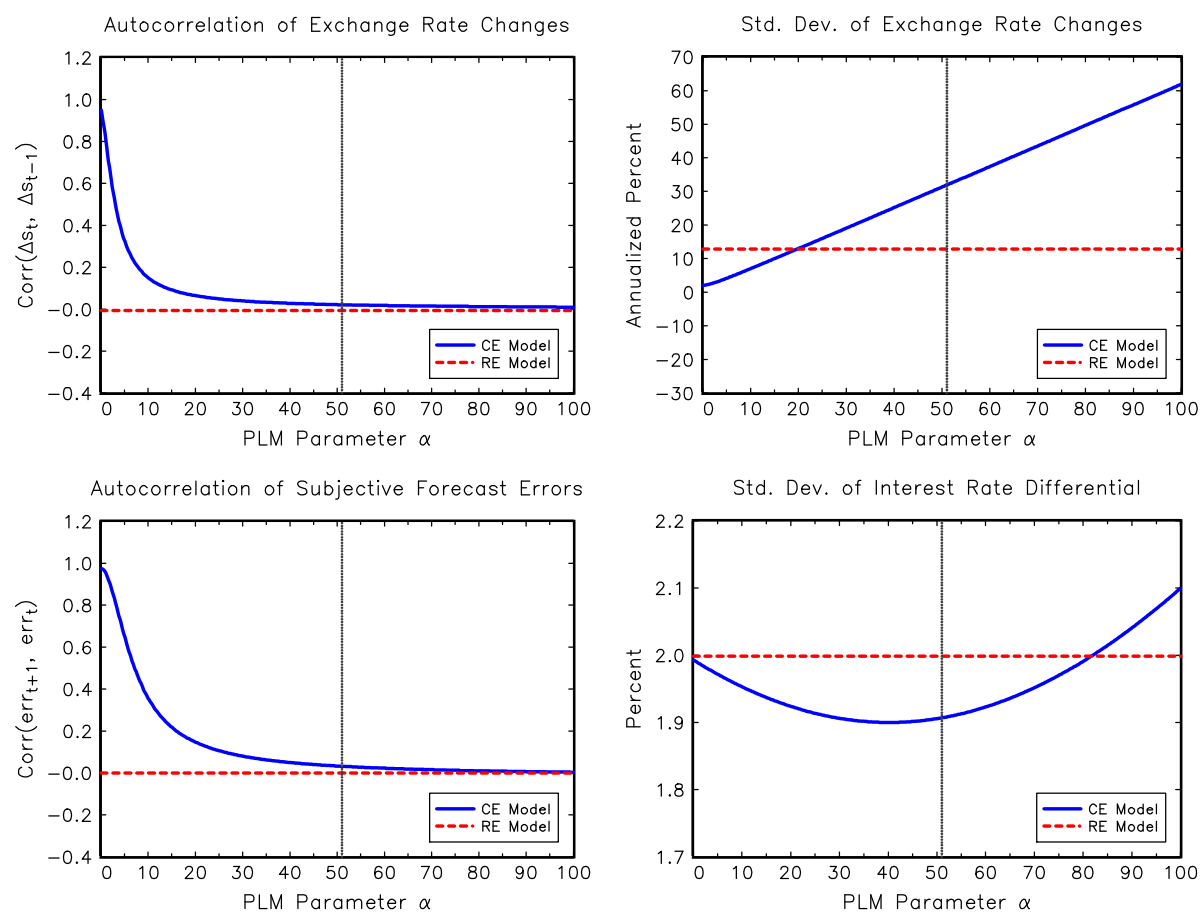

Figure 3: At the unique fixed point equilibrium, the standard deviation of exchange rate changes in the consistent expectations model $(\mathrm{CE})$ is more than twice that in the rational expectations (RE) model. In equilibrium, the forecast errors observed by the agent in the CE model are close to white noise, making it difficult for the agent to detect a misspecification of the subjective forecast rule. The vertical line marks the equilibrium value $\alpha=\alpha^{*}=51$.

deviation of $\Delta s_{t}$ in both the $\mathrm{CE}$ and $\mathrm{RE}$ models. The autocorrelation of $\Delta s_{t}$ is close to zero in both models, reflecting a near-unit root in the level of the exchange rate $s_{t}$. Notice, however, that the $\mathrm{CE}$ model delivers substantial excess volatility relative to the RE model. When $\alpha=\alpha^{*}$, the standard deviation of $\Delta s_{t}$ in the CE model is more than twice that in the RE model. Due to the misspecified nature of the agent's PLM in the CE model, a large value of $\alpha$ is needed to account for the behavior of the exchange rate data that the agent actually observes.

The bottom-left panel of Figure 3 plots the autocorrelation of the agent's forecast errors in each model. The autocorrelation is exactly zero in the RE model. When $\alpha=\alpha^{*}$, the subjective forecast rule in the CE model performs well in the sense that it delivers a nearzero autocorrelation of the forecast errors, making it difficult for the agent to detect any misspecification.

The bottom-right panel of Figure 3 plots the theoretical standard deviation of the interest rate differential $i_{t}-i_{t}^{*}$. At the equilibrium value $\alpha=\alpha^{*}$, the volatility of $i_{t}-i_{t}^{*}$ in the CE model is slightly below the volatility implied by the RE solution. Hence, the CE model's 


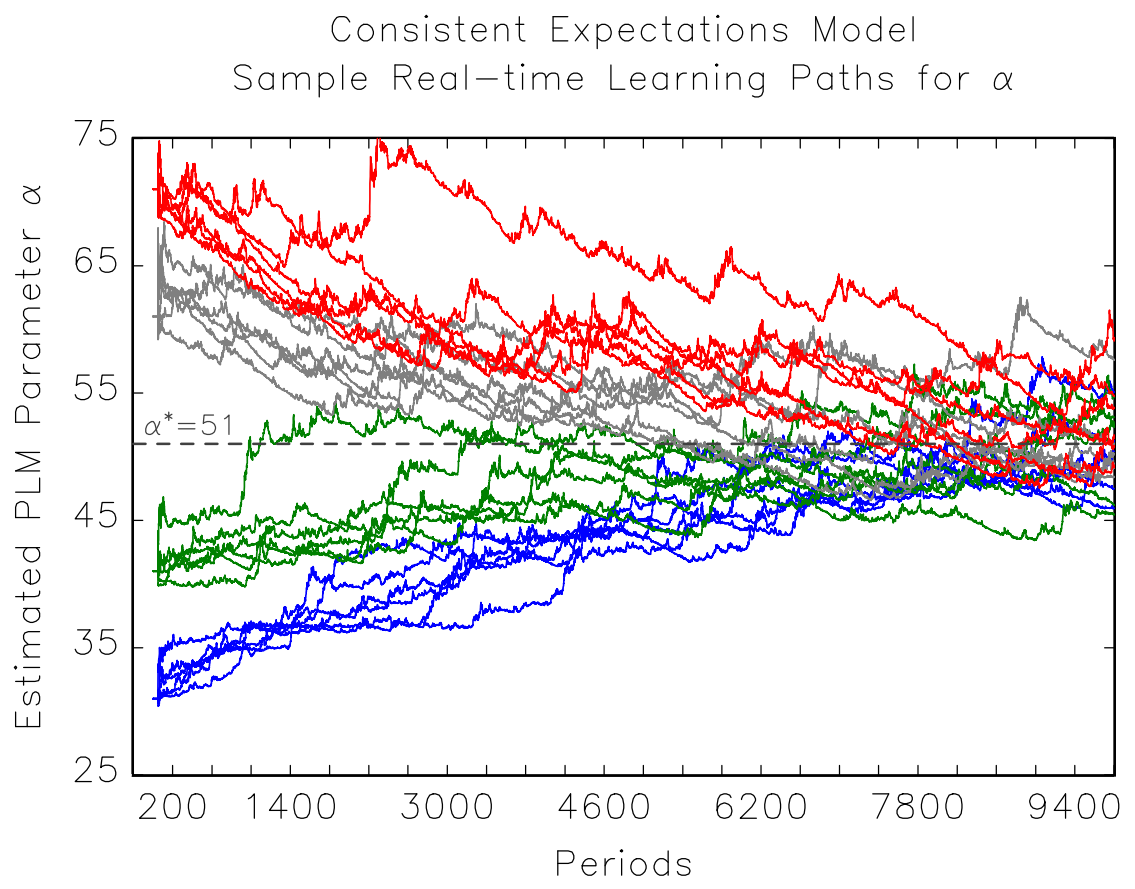

Figure 4: The figure plots twenty-four separate real-time learning paths (grouped by starting value) for the PLM parameter $\alpha$. The simulations confirm that the consistent expectations equilibrium is learnable; the estimated value of $\alpha$ eventually converges to the vicinity of the theoretical fixed point value $\alpha^{*}=51$, regardless of the shock sequences or the starting value for $\alpha$.

excess volatility in $\Delta s_{t}$ is not being driven by excess volatility in the interest rate differential, but rather is driven by agents' self-referential expectations.

Table 3 shows the theoretical moments in the CE model as predicted by the perceived law of motion (12) and the actual law of motion (14). The moments of $\Delta s_{t}$ observed by the agent are very close to those predicted by the PLM, helping to confirm the agent's belief that the PLM is correctly specified.

Table 3. Theoretical Moments of $\Delta s_{t}$

\begin{tabular}{cccc}
\hline \hline & \multicolumn{2}{c}{ CE Model } & RE Model \\
Statistic & PLM (predicted) & ALM (observed) & PLM = ALM \\
\hline $\operatorname{Std} \operatorname{Dev}\left(\Delta s_{t}\right)$ & $31.85 \%$ & $31.91 \%$ & $12.79 \%$ \\
$\operatorname{Corr}\left(\Delta s_{t}, \Delta s_{t-1}\right)$ & 0 & 0.0216 & -0.0059 \\
$\operatorname{Corr}\left(\Delta s_{t}, \Delta s_{t-2}\right)$ & 0 & 0.0205 & -0.0243 \\
$\operatorname{Corr}\left(\Delta s_{t}, \Delta s_{t-3}\right)$ & 0 & 0.0194 & -0.0235 \\
\hline Notes: Parameter values are $b=0.9804, \kappa=0.98, \rho=0.95, \sigma_{u}=0.00624, \alpha=\alpha^{*}=51$.
\end{tabular}



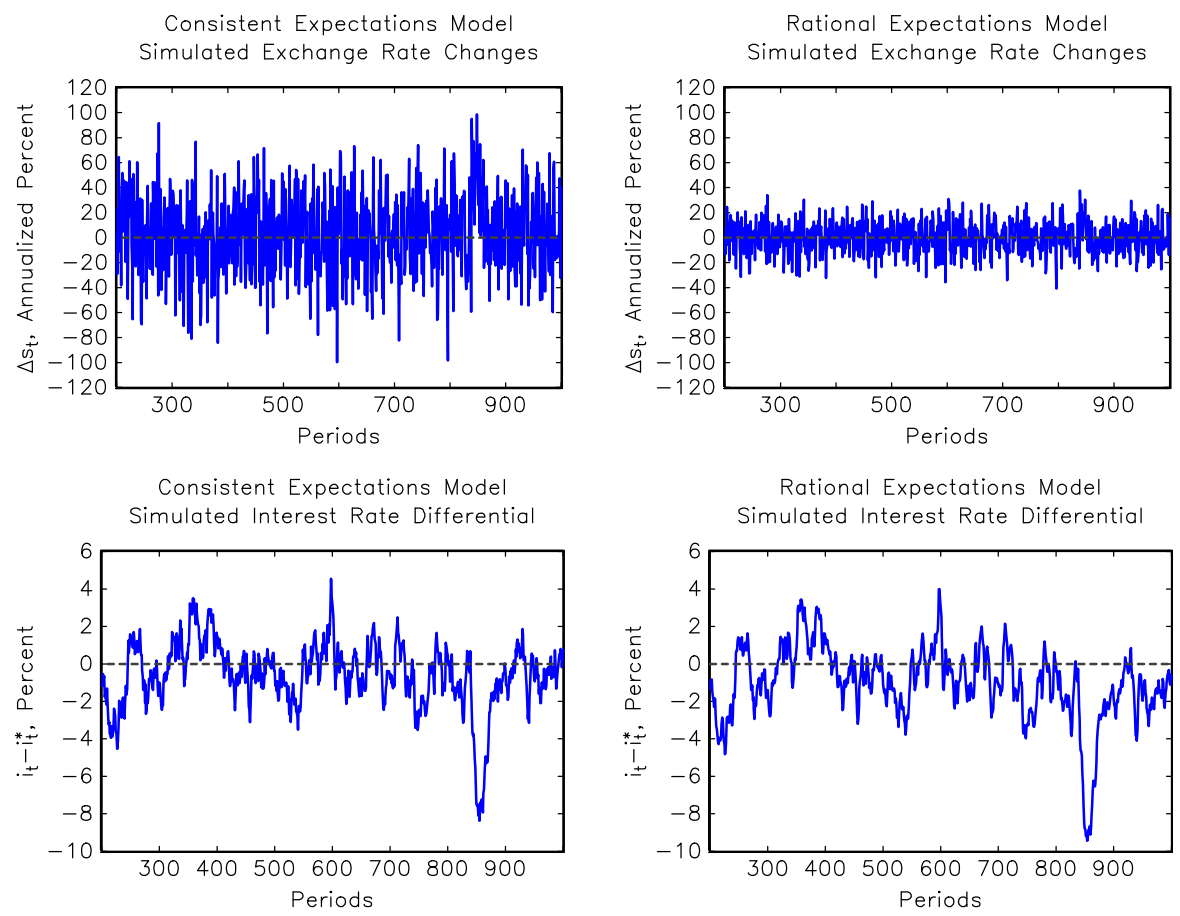

Figure 5: The consistent expectations (CE) model generates much more volatility in the exchange rate change $\Delta s_{t}$ than the rational expectation (RE) model . Both model solutions exhibit similar volatility for the interest rate differential $i_{t}-i_{t}^{*}$.

\subsection{Model Simulations}

Figure 4 plots twenty-four separate real-time learning paths (grouped by starting value) for the fundamental news response parameter $\alpha$ that appears in the PLM. Other parameters are set to the same values shown in Table 4 . We employ four separate starting values $\alpha_{0} \in\{31,41,61,71\}$ that initially enter the ALM (14), with each learning path subject to a different sequence of draws for the fundamental innovation $u_{t}$. Each period, a new value for $\alpha$ is computed from past observable data using equation (15) and then substituted into the ALM and so on.

Since the effective discount factor $b$ is close to unity, the map $T(\alpha)$ from Definition 1 lies very close to 45-degree line. Due to the shape of the map, a small amount of sampling variation in the relevant covariance statistic can translate into sizable shifts in the estimated value of $\alpha$, resulting in slow convergence to $\alpha^{*}$. To speed up the learning process, we assume that the covariance statistic is computed using a 15-year (180-month) rolling sample period. The simulations confirm that the consistent expectations equilibrium is learnable; the estimated value of $\alpha$ eventually converges to the vicinity of the theoretical fixed point value $\alpha^{*}=51$, regardless of the starting value. 
Figure 5 plots simulated values for $\Delta s_{t}$ and $i_{t}-i_{t}^{*}$ for both models. The simulations confirm the theoretical results presented earlier in Table 3; the CE model generates considerably more volatility in $\Delta s_{t}$ relative to the RE model. This is true despite the fact that CE model exhibits a slightly lower volatility for the interest rate differential, as shown by the bottom panels of Figure 5 .

Table 4 compares the moments observed in the data to those generated by the model simulations. The CE model does a remarkably good job of matching all of the data moments. The $\mathrm{CE}$ model and the RE model can both generate near-random walk behavior of the exchange rate such that $\operatorname{Corr}\left(\Delta s_{t}, \Delta s_{t-1}\right) \simeq 0$ and $\operatorname{Corr}\left(\Delta^{2} s_{t}, \Delta^{2} s_{t-1}\right) \simeq-0.5$, where $\Delta^{2} s_{t} \equiv \Delta s_{t}-\Delta s_{t-1}$ is the second difference of the exchange rate. However, the CE model generates much higher volatility in $\Delta s_{t}$ and $\Delta^{2} s_{t}$, consistent with the data.

The middle rows of Table 4 confirm that the moments of the interest rate differential $i_{t}-i_{t}^{*}$ in both models are close to those observed in the data. This is true even though we have not attempted to customize the values of the Taylor rule parameters to the data for each country. Finally, the bottom row of Table 4 shows that the CE model produces a negative correlation between $\Delta s_{t+1}$ and the prior interest rate differential $i_{t}-i_{t}^{*}$. The negative correlation is consistent with the data in all three countries and with the typical negative sign of the slope coefficient in empirical UIP regressions, to be discussed next.

Table 4. Unconditional Moments: Data versus Model Simulations

\begin{tabular}{lrrrrr}
\hline \hline & & & & CE & \multicolumn{1}{c}{ RE } \\
& Canada & Japan & U.K. & Model & \multicolumn{1}{c}{ Model } \\
\hline Std Dev $\left(\Delta s_{t}\right)$ & $22.7 \%$ & $38.3 \%$ & $35.6 \%$ & $31.9 \%$ & $12.8 \%$ \\
$\operatorname{Corr}\left(\Delta s_{t}, \Delta s_{t-1}\right)$ & -0.054 & 0.055 & 0.093 & 0.021 & -0.008 \\
$\operatorname{Std}$ Dev $\left(\Delta^{2} s_{t}\right)$ & $(0.046)$ & $(0.046)$ & $(0.046)$ & $(0.010)$ & $(0.010)$ \\
$\operatorname{Corr}\left(\Delta^{2} s_{t}, \Delta^{2} s_{t-1}\right)$ & $33.0 \%$ & $52.5 \%$ & $48.0 \%$ & $44.6 \%$ & $18.1 \%$ \\
$\operatorname{Std} \operatorname{Dev}\left(i_{t}-i_{t}^{*}\right)$ & -0.535 & -0.493 & -0.467 & -0.506 & -0.497 \\
$\operatorname{Corr}\left(i_{t}-i_{t}^{*}, i_{t-1}-i_{t-1}^{*}\right)$ & $(0.033)$ & $(0.035)$ & $(0.036)$ & $(0.008)$ & $(0.008)$ \\
\hline \multirow{2}{*}{$\operatorname{Corr}\left(\Delta s_{t+1}, i_{t}-i_{t}^{*}\right)$} & $1.62 \%$ & $2.35 \%$ & $2.18 \%$ & $1.92 \%$ & $2.04 \%$ \\
& 0.956 & 0.972 & 0.954 & 0.953 & 0.975 \\
& $(0.004)$ & $(0.003)$ & $(0.004)$ & $(0.001)$ & $(0.001)$ \\
\hline
\end{tabular}

Notes: Data sample period is from 1974.m1 to 2012.m10. CE = consistent expectations. RE = rational expectations. Model statistics are computed from a 10,000 period simulation. Numbers in parentheses are the standard errors of the correlation coefficients.

\subsection{UIP Regressions}

Table 5 compares the results of UIP regressions using country data to those using modelgenerated data. In addition to the full-sample estimates for Canada, Japan, and the U.K. reported earlier in Table 1, we now also report the mean results from 15-year rolling regressions 

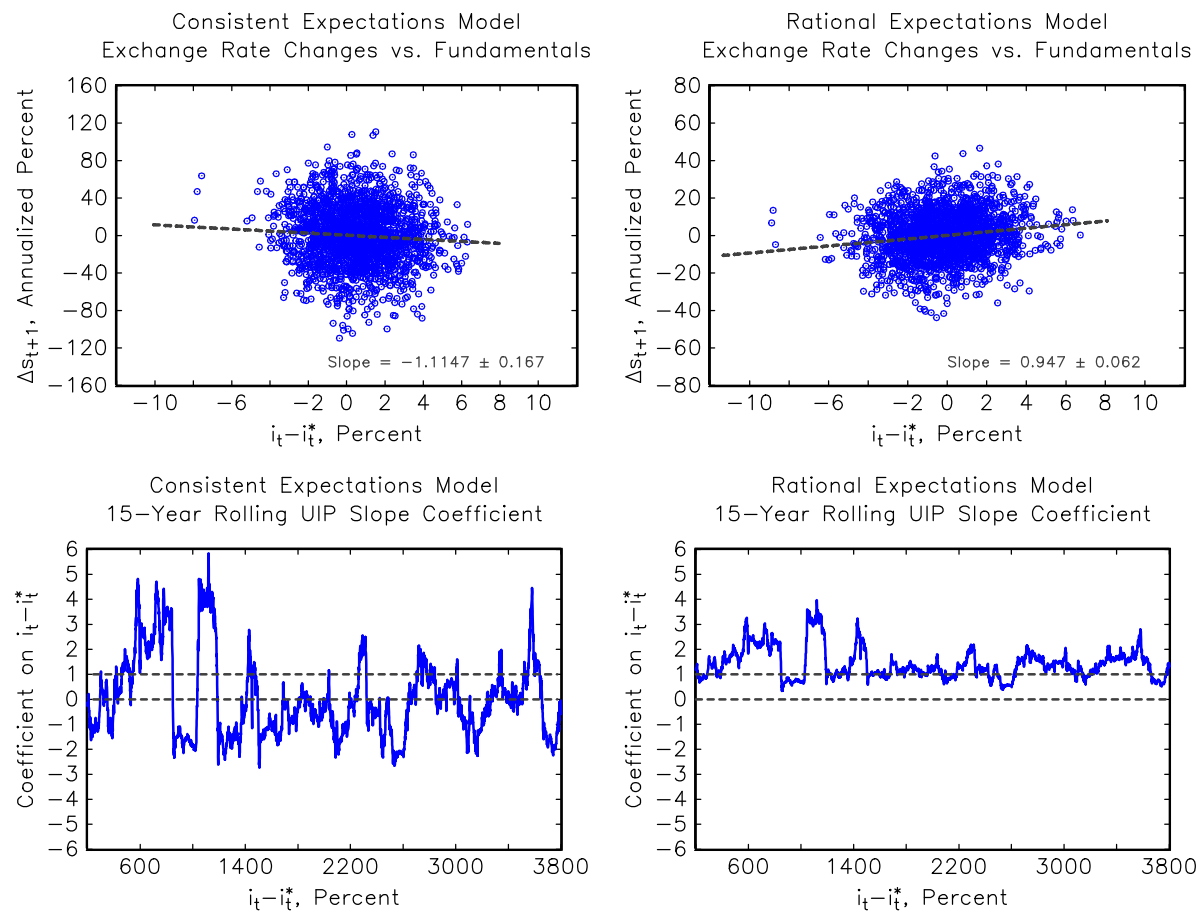

Figure 6: The fitted relationship between $\Delta s_{t+1}$ and $i_{t}-i_{t}^{*}$ in the consistent expectations (CE) model exhibits a negative slope coefficient, similar to the country data plotted in Figure 1. The estimated UIP slope coefficient in the CE model exhibits considerable time variation, similar to the data estimates shown in Figure 2. In contrast, the rational expectations (RE) model exhibits a positive UIP slope coefficient with much less time variation.

for each country. Figure 6 presents the model-generated analogs to the country data plots shown earlier in Figures 1 and 2. Specifically, the top panels of Figure 6 show scatter plots of the simulated exchange rate change $\Delta s_{t+1}$ versus the prior interest rate differential $i_{t}-i_{t}^{*}$ in both models. The dashed lines show the fitted relationships from the full-sample UIP regressions, with details reported in Table 5. The bottom panels of Figure 6 plot the estimated slope coefficients from UIP regressions using 15-year rolling sample periods.

Table 5 shows that the estimated UIP slope coefficients for Canada, Japan, and the U.K. are all negative, illustrating the forward-premium anomaly. The $R^{2}$ statistics from these regressions are all close to zero, illustrating the exchange rate disconnect puzzle. The CE model produces a negative UIP slope coefficient in the full-sample regression. The rollingregression estimates for the $\mathrm{CE}$ model deliver a mean slope coefficient that is slightly positive at 0.19 , with a mean standard error of 1.5. The larger standard error is due to the smaller sample size. Similar to the country data, the rolling-regression estimates for the CE model are not statistically different from zero. The $R^{2}$ statistics for the CE model are very low, similar to those in the data. Another realistic feature of the CE model, evident in the bottom-left 
panel of Figure 6, is the considerable time variation in the estimated slope coefficient from rolling regressions. Similar time variation can be seen in the country-data rolling regressions plotted earlier in Figure 2.

The rolling-regression estimates for the RE model are always in positive territory, exhibit much smaller time variation, and cluster around one. Interestingly, the RE model can account for the exchange rate disconnect puzzle as it produces a very small $R^{2}$ statistic in both the full-sample and rolling regressions. This result is consistent with the arguments put forth by Engel and West $(2005,2006)$ who show that a fully-rational model with highly-persistent fundamentals and a discount factor close to one can deliver near-random walk behavior of the exchange rate such that changes in the exchange rate are nearly unpredictable using fundamentals. Still, the RE model fails to account for the forward premium anomaly and woefully underpredicts the observed volatility of exchange rate changes in the data (Table 4).

Table 5. UIP Regressions: Data versus Models

\begin{tabular}{|c|c|c|c|c|c|}
\hline $\begin{array}{l}\text { Full-Sample } \\
\text { Estimates }\end{array}$ & Canada & Japan & U.K. & $\begin{array}{c}\text { CE } \\
\text { Model }\end{array}$ & $\begin{array}{c}\mathrm{RE} \\
\text { Model }\end{array}$ \\
\hline $\begin{array}{l}\widehat{\beta}_{1} \\
R^{2}\end{array}$ & $\begin{array}{r}-0.29 \\
(0.65) \\
0.007\end{array}$ & $\begin{array}{r}-1.86 \\
(0.75) \\
0.013\end{array}$ & $\begin{array}{r}-1.21 \\
(0.76) \\
0.005\end{array}$ & $\begin{array}{r}-1.10 \\
(0.17) \\
0.004\end{array}$ & $\begin{array}{l}0.95 \\
(0.06) \\
0.023\end{array}$ \\
\hline $\begin{array}{l}\text { Mean 15-year } \\
\text { Rolling Estimates }\end{array}$ & Canada & Japan & U.K. & $\begin{array}{c}\text { CE } \\
\text { Model }\end{array}$ & $\begin{array}{c}\mathrm{RE} \\
\text { Model }\end{array}$ \\
\hline $\begin{array}{l}\widehat{\beta}_{1} \\
R^{2}\end{array}$ & $\begin{array}{r}-1.68 \\
(1.08) \\
0.024 \\
\end{array}$ & $\begin{array}{r}-2.79 \\
(1.48) \\
0.020 \\
\end{array}$ & $\begin{array}{r}-0.78 \\
(1.44) \\
0.020 \\
\end{array}$ & $\begin{array}{l}0.19 \\
(1.50) \\
0.008 \\
\end{array}$ & $\begin{array}{l}1.46 \\
(0.56) \\
0.036\end{array}$ \\
\hline $\begin{array}{l}\text { Notes: The table show } \\
\text { covers the period from } \\
\text { expectations. Numbers } \\
\text { a } 10,000 \text { period simula }\end{array}$ & $\begin{array}{l}\text { ults of a } \\
\text { to } 2012 \\
\text { ntheses a }\end{array}$ & $\begin{array}{l}\text { regress } \\
\mathrm{CE}= \\
\text { andard } \mathrm{e}\end{array}$ & $\begin{array}{l}\mathrm{n} \text { the for } \\
\text { stent ex } \\
\text { Model }\end{array}$ & $\begin{array}{l}\text { f equatio } \\
\text { ations. } \mathrm{R} \\
\text { istics are }\end{array}$ & $\begin{array}{l}\text { The dat } \\
\text { rational } \\
\text { puted fro }\end{array}$ \\
\hline
\end{tabular}

\subsection{Forecast Error Comparison}

Proposed departures from rational expectations are often criticized on the grounds that intelligent agents would eventually detect the misspecification of their subjective forecast rule. We counter this criticism in two ways. First, we show that the autocorrelation structure of the subjective forecast errors in the CE model are close to white noise, making it difficult for an agent to detect any misspecification. Second, we show that the forecast performance of the representative agent in the CE model is nearly as good as a hypothetical agent who is endowed with knowledge of the actual law of motion (14). Hence, there is very little reward available in the model for an individual agent who may wish to expend resources searching for a better forecast rule.

From equation (13), the forecast errors observed by the representative agent in the CE 
model are given by

$$
\begin{aligned}
\operatorname{err}_{t}^{\mathrm{PLM}} & =s_{t+1}-\widehat{E}_{t} s_{t+1}, \\
& =s_{t+1}-s_{t-1}-\alpha u_{t}
\end{aligned}
$$

where we use the superscript "PLM" to indicate that $\widehat{E}_{t} s_{t+1}$ is based on the perceived law of motion (12). But of course, the evolution of $s_{t+1}$ is governed by the ALM (14).

Now consider an atomistic agent who understands that the evolution of $s_{t+1}$ is governed by the ALM. This hypothetical agent cannot influence the evolution of $s_{t+1}$ but is tasked only with making forecasts. The forecast error observed by the hypothetical agent is given by

$$
e r r_{t+1}^{\mathrm{ALM}}=s_{t+1}-[1-(1-\kappa)(1-b)] s_{t}-\rho x_{t}
$$

where we use the superscript "ALM" to indicate that the forecast is based on the actual law of motion. Notice that, unlike the representative agent in the CE model, we allow the hypothetical agent's forecast to make use of the contemporaneous realization of the exchange rate $s_{t}$.

Within the RE model, the forecast errors observed by the fully-rational agent are given by

$$
\begin{aligned}
e r r_{t+1}^{\mathrm{RE}} & =s_{t+1}-\left(a_{s} s_{t}+a_{x} \rho x_{t}\right) \\
& =a_{x} u_{t+1} .
\end{aligned}
$$

Given the sequences of forecast errors, it is straightforward to compute the associated autocorrelations and the root mean squared forecast error, as given by $\left.R M S F E \equiv \sqrt{E\left[\left(e r r_{t+1}\right)^{2}\right.}\right]$. In each of the above cases, the forecasts are unbiased such that $E\left(e r r_{t+1}\right)=0$.

Table 6 compares the moments of the various forecast errors computed from model simulations. For the PLM-based forecast, the autocorrelations of the forecast errors are near zero at all lags, giving the agent in the $\mathrm{CE}$ model no significant indication of a misspecification. The ALM-based forecast of the hypothetical agent delivers a slightly lower RMSFE of $31.8 \%$ versus $32.1 \%$ for the PLM-based forecast. Hence, there is little room for an individual agent in the CE model to improve forecasting performance by employing more sophisticated (and presumably more costly) econometric methods to discover the true underlying law of motion for the exchange rate.

The last column of Table 6 shows that the RE model exhibits the most accurate forecasts (lowest $R M S F E$ ), as expected. However, it is important to realize that an individual agent inhabiting the CE model could never achieve this level of forecast performance unless all of the other agents decided to switch to the fully-rational forecast rule. This is because the actual law of motion for the exchange rate in the $\mathrm{CE}$ model is permanently shifted by the forecasting behavior of the CE agents. 
Table 6. Comparison of Forecast Errors

\begin{tabular}{lccc}
\hline \hline & \multicolumn{2}{c}{ CE Model } & \\
\cline { 2 - 3 } & $\begin{array}{c}\text { PLM-based } \\
\text { Forecast }\end{array}$ & $\begin{array}{c}\text { ALM-based } \\
\text { Forecast }\end{array}$ & RE Model \\
\hline $\operatorname{Corr}\left(\operatorname{err}_{t+1}, \operatorname{err}_{t}\right)$ & 0.032 & -0.001 & -0.001 \\
$\operatorname{Corr}\left(\operatorname{err}_{t+1}, \operatorname{err}_{t-1}\right)$ & 0.061 & 0.011 & 0.011 \\
$\operatorname{Corr}\left(\operatorname{err}_{t+1}, \operatorname{err}_{t-2}\right)$ & 0.048 & 0.000 & 0.000 \\
$\sqrt{\operatorname{Mean}\left(\operatorname{err}_{t+1}^{2}\right)}$ & $32.1 \%$ & $31.8 \%$ & $12.63 \%$ \\
\hline
\end{tabular}

Notes: Forecast errors are defined by equations (21) through (23). Model statistics are computed

from a 10,000 period simulation. $\mathrm{RE}=$ rational expectations, $\mathrm{CE}=$ consistent expectations, $\mathrm{PLM}=$ perceived law of motion from equation (12), ALM = actual law of motion from equation (14).

\section{Plausibility of the Subjective Forecast Rule}

In this section, we use real-world data to gauge the empirical plausibility of the subjective forecast rule (13). Table 7 reports the average root mean squared forecast errors (RMSFE) for five different forecast rules. The $R M S F E$ statistics are computed sequentially using a 3 -year rolling sample period and then averaged. The initial sample period is from 1974.m1 to 1977.m1. We use a 3 -year window to capture the idea that asset market participants are typically concerned with the recent performance of alternative forecasting and trading strategies. The first two rows of the table show the results for a random walk forecast using either contemporaneous or lagged information about the exchange rate. The third and fourth rows show forecast rules in which the random walk forecast is augmented with a term that responds to fundamental news. Again we distinguish between the use of contemporaneous or lagged information about the exchange rate. ${ }^{24}$ The fifth row shows results for a fundamentalsonly forecast where the coefficients $\mathrm{f}_{0, t}$ and $\mathrm{f}_{1, t}$ are estimated sequentially for each rolling sample period using data for each country's fundamental driving variable $x_{t}$.

\footnotetext{
${ }^{24}$ To construct the fundamental news term, we sequentially estimate the law of motion for fundamentals (8) for each 3-year (36-month) rolling sample period and use the resulting parameter estimates to identify a sequence of fundamental innovations $u_{t}$ for that sample period. We then estimate the response coefficient on fundamental news using either contemporaneous information about the exchange rate, i.e., $\alpha_{t}=\operatorname{Cov}\left(\Delta s_{t}, u_{t}\right) / \operatorname{Var}\left(u_{t}\right)$ or lagged information about the exchange rate $\alpha_{t-1}=\operatorname{Cov}\left(\Delta s_{t-1}, u_{t-1}\right) / \operatorname{Var}\left(u_{t}\right)$.
} 
Table 7. Average 3-year Rolling RMSFE

\begin{tabular}{lccc}
\hline \hline Forecast Rule & Canada & Japan & UK \\
\hline$\widehat{E}_{t} s_{t+1}=s_{t}$ & $20.9 \%$ & $38.3 \%$ & $35.1 \%$ \\
$\widehat{E}_{t} s_{t+1}=s_{t-1}$ & $29.0 \%$ & $56.0 \%$ & $51.3 \%$ \\
$\widehat{E}_{t} s_{t+1}=s_{t}+\alpha_{t} u_{t}$ & $24.9 \%$ & $48.4 \%$ & $41.1 \%$ \\
$\widehat{E}_{t} s_{t+1}=s_{t-1}+\alpha_{t-1} u_{t}$ & $26.5 \%$ & $48.5 \%$ & $44.6 \%$ \\
$\widehat{E}_{t} s_{t+1}=\mathrm{f}_{0, t}+\mathrm{f}_{1, t} x_{t}$ & $66.5 \%$ & $123.5 \%$ & $117.7 \%$ \\
\hline \multicolumn{4}{l}{ Notes: Root mean squared forecast errors $(R M S F E)$ are computed } \\
sequentially using a 3-year rolling sample period and then averaged. \\
\multicolumn{5}{l}{ The initial sample period is from 1974.m1 to 1977.m1. }
\end{tabular}

Consistent with many previous studies, the top row of Table 7 shows that a random walk forecast using contemporaneous information has the lowest RMSFE and thus outperforms the other four forecast rules. Nevertheless, as mentioned earlier, survey evidence indicates that market participants continue to employ information about fundamentals when constructing their forecasts. The fundamentals-only forecast in the bottom row exhibits the worst performance with the highest $R M S F E$.

For comparison with the CE model, our main interest is asking whether the use of fundamental news can improve the performance of a random walk forecast that uses lagged information about the exchange rate. The answer is yes. Comparing the second and fourth rows of Table 7 shows that the inclusion of fundamental news together with the lagged exchange rate helps to improve forecast accuracy relative to an otherwise similar random walk forecast that omits the fundamental news term.

It is also instructive to compare the third and fourth rows of Table 7 . These results show that once the fundamental news term is included in the forecasting regression, the use of contemporaneous information about the exchange rate delivers very little improvement in forecast performance relative to an otherwise similar forecast rule that uses lagged information.

The results in Table 7 represent averages over the entire sequence of rolling sample periods. In Figure 7, we plot the sequence of 3-year rolling RMSFEs for each country. The bottom right panel shows the ratio of the RMSFE for a forecast using lagged information about the exchange rate relative to the $R M S F E$ for a forecast using contemporaneous information about the exchange rate. The ratios are below one for a substantial portion of data sample, indicating that a lagged information forecast rule is often more accurate over a 3-year window. These results lend support to the plausibility of the subjective forecast rule (13) in the CE model.

It is also useful to consider direct evidence on whether professional forecasters behave in a way that is consistent with the CE model. We noted earlier that the vast majority of professional forecasters report using fundamental economic data to help construct their forecasts. In support of this idea, Figure 8 shows scatter plots of the forecasted 3-month ahead exchange rate change from a survey of professional forecasters versus the change in the 

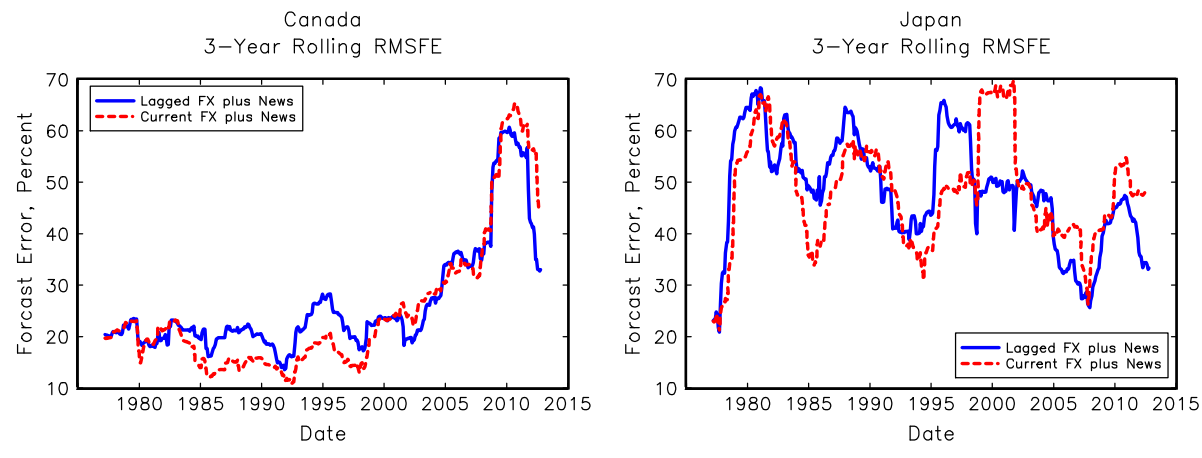

United Kingdom

3-Year Rolling RMSFE
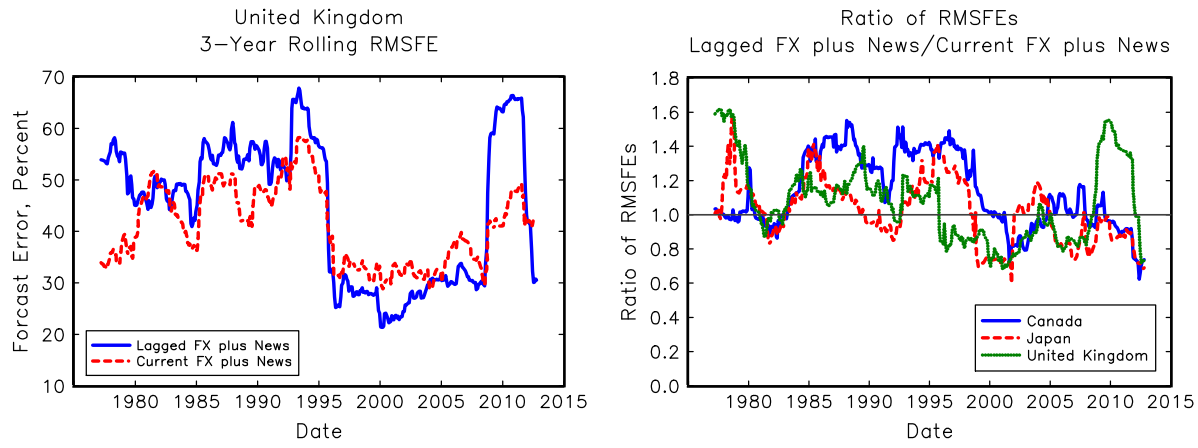

Figure 7: The inclusion of fundamental news together with the lagged exchange rate helps to improve forecast accuracy relative to an otherwise similar random walk forecast that omits the fundamental news term. Moreover, once the fundamental news term is included in the forecasting regression, forecast performance is often improved by using the lagged exchange rate rather than the contemporaneous exchange rate.

country's interest rate differential - a proxy for fundamental news. ${ }^{25}$ Specifically, a positive change in the interest rate differential $i_{t}-i_{t}^{*}$ is a proxy for $-u_{t}$ since, as shown earlier, the fundamental driving variable $x_{t}$ is negatively correlated with the interest rate differential. The estimated slope coefficients for the scatter plots are all negative, but in some cases (Canada and Japan) are not statistically different from zero. The pooled data scatter plot shows that the survey respondents tend to forecast a statistically significant negative change in the exchange rate (a forecasted appreciation) in response to a positive change in the interest rate differential, which is a proxy for $-u_{t}$. When $\alpha>0$, the subjective forecast rule (13) in the CE model also predicts a negative change in the exchange rate in response to a negative realization of $u_{t}$.

\footnotetext{
${ }^{25}$ The survey forecasts for the Canada/U.S., Japan/U.S., and U.K./U.S. exchange rate are the consensus values from a monthly survey of a large number of financial institutions, as compiled by FX4casts.com. The survey dates cover the period 1986.m8 to 2012.m10.
} 

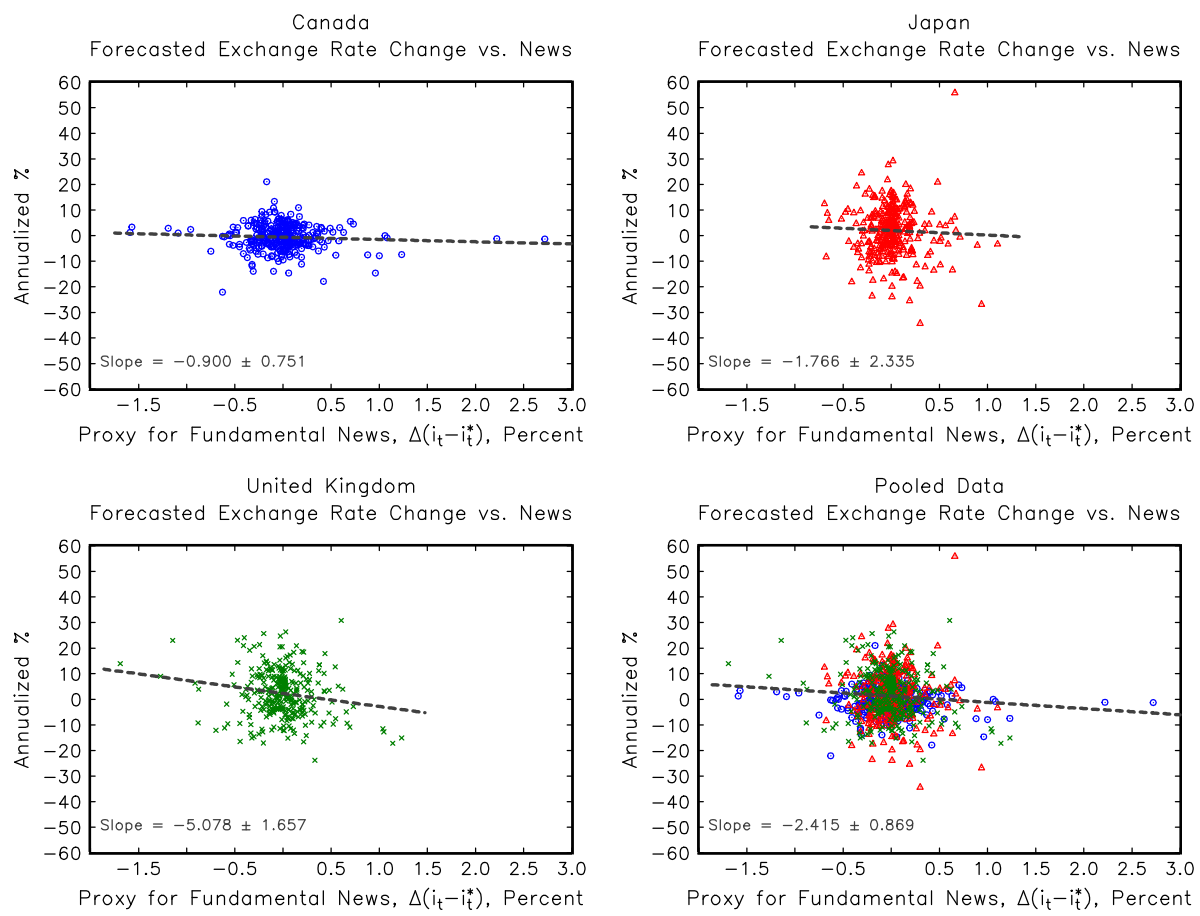

Figure 8: Changes in the interest rate differential (a proxy for fundamental news) are helpful in explaining movements in the survey forecasts - a result that is consistent with the subjective forecast rule in the CE model. The survey respondents tend to forecast a currency appreciation during periods when the change of interest rate differential is positive.

\section{Concluding Remarks}

A reading of the last three decades of academic research on exchange rates highlights numerous puzzles and anomalies that have stubbornly resisted explanation, particularly in the context of models where all agents are fully-rational. This paper shows that a plausible small departure from full rationality - in the form of boundedly-rational agents who augment a lagged-information random walk forecast with news about fundamentals - can account for several empirical exchange rate puzzles, including the apparent disconnect from fundamentals, the very high volatility of exchange rate changes relative to fundamentals, and the failure of exchange rates to satisfy the UIP condition. Our paper relates to the literature on boundedrationality and is the first to be able to replicate jointly the exchange rate puzzles mentioned above. Given that real-world exchange rates exhibit near-random walk behavior, it makes sense that agents would adopt a forecast rule that allows for a unit root. Our model setup is also consistent with survey data which shows that professional exchange rate forecasts respond to movements in fundamental news, as measured by changes in cross-country interest rate differentials. 


\section{A Appendix: Proof of Proposition 1}

The characteristic equation of the stochastic difference equation (6) is given by

$$
\mathrm{f}(r)=r^{2}-\frac{1}{b} r+\frac{\kappa(1-b)}{b}=0,
$$

We denote the two roots of equation (A.1) as $r_{1}$ and $r_{2}$. Inserting these roots into the equation and applying some algebra yields the following relationships

$$
\begin{aligned}
r_{1} r_{2} & =\frac{\kappa(1-b)}{b}>0 \\
r_{1}+r_{2} & =\frac{1}{b}>0 \\
\left(r_{1}-1\right)\left(r_{2}-1\right) & =r_{1} r_{2}-\left(r_{1}+r_{2}\right)+1 \\
& =\frac{\kappa(1-b)}{b}-\frac{1}{b}+1 \\
& =\frac{(\kappa-1)(1-b)}{b}<0
\end{aligned}
$$

Since $\left(r_{1}-1\right)\left(r_{2}-1\right)<0$, one root is greater than one and the other is less than one. Also because $r_{1} r_{2}>0$ and $r_{1}+r_{2}>0$ it must be true that both roots are positive. Therefore we can conclude that one root is greater than unity and the other root is positive but less than unity. Since we have one initial condition that pins down $s_{t-1}$, there exists a unique rational expectation solution (Blanchard and Kahn 1980).

We postulate that the solution to equation (6) takes the form: $s_{t}=a_{s} s_{t-1}+a_{x} x_{t}$, where $a_{s}$ and $a_{x}$ are undetermined coefficients. Iterating the postulated solution ahead one period and taking the rational expectation yields $E_{t} s_{t+1}=a_{s} s_{t}+a_{x} \rho x_{t}$. Substituting this expectation into (6) and collecting terms yields

$$
s_{t}=\underbrace{\frac{\kappa(1-b)}{1-b a_{s}}}_{=a_{s}} s_{t-1}+\underbrace{\frac{1+b a_{x} \rho}{1-b a_{s}}}_{=a_{x}} x_{t},
$$

which shows that the postulated form is correct. The value of $a_{s}$ must satisfy

$$
b\left(a_{s}\right)^{2}-a_{s}+\kappa(1-b)=0,
$$

which has two solutions. The stable solution is the one that delivers $\left|a_{s}\right|<1$. This is

given by $a_{s}=[1-\sqrt{1-4 \kappa b(1-b)}] /(2 b)$. Given $a_{s}$, the value of $a_{x}$ must satisfy $a_{x}=$ $1 /\left[1-b\left(a_{s}+\rho\right)\right]$. 


\section{B Appendix: Moments with Rational Expectations}

Using the law of motion for $s_{t}$ from Proposition 1, straightforward computations yield the following unconditional moments.

$$
\begin{aligned}
& \frac{\operatorname{Var}\left(s_{t}\right)}{\operatorname{Var}\left(x_{t}\right)}=\frac{a_{x}^{2}}{\left(1-a_{s}^{2}\right)}\left[\frac{1+a_{s} \rho}{1-a_{s} \rho}\right] \\
& \frac{\operatorname{Var}\left(\Delta s_{t}\right)}{\operatorname{Var}\left(x_{t}\right)}=\frac{2 a_{x}^{2}(1-\rho)}{\left(1+a_{s}\right)\left(1-a_{s} \rho\right)}, \\
& \operatorname{Corr}\left(s_{t}, s_{t-1}\right)=\frac{a_{s}+\rho}{1+a_{s} \rho}, \\
& \frac{\operatorname{Cov}\left(\Delta s_{t+1}, i_{t}-i_{t}^{*}\right)}{\operatorname{Var}\left(x_{t}\right)}=\frac{a_{x}}{b}\left\{\frac{\left(a_{s}-1\right)(1-b)\left(1-\kappa a_{s}\right) a_{x}\left(1+a_{s} \rho\right)}{\left(1-a_{s}^{2}\right)\left(1-a_{s} \rho\right)}-\rho\right\}+ \\
& \frac{a_{x}}{b}\left\{\frac{\left[-\rho \kappa a_{x}(1-b)-1\right]\left(a_{s}-1\right)+\rho a_{x}(1-b)(1-\rho \kappa)}{1-a_{s} \rho}\right\} \\
& \frac{\operatorname{Var}\left(i_{t}-i_{t}^{*}\right)}{\operatorname{Var}\left(x_{t}\right)}=\frac{\operatorname{Cov}\left(\Delta s_{t+1}, i_{t}-i_{t}^{*}\right)}{\operatorname{Var}\left(x_{t}\right)},
\end{aligned}
$$

where $\operatorname{Var}\left(x_{t}\right)=\sigma_{u}^{2} /\left(1-\rho^{2}\right)$.

\section{Appendix: Moments with Consistent Expectations}

Using the actual laws of motion (14) and (16), straightforward but tedious computations yield the following unconditional moments.

$$
\begin{aligned}
\frac{\operatorname{Var}\left(s_{t}\right)}{\operatorname{Var}\left(x_{t}\right)}= & \frac{1+\left(b^{2} \alpha^{2}+2 b \alpha\right)\left(1-\rho^{2}\right)+\frac{2 \rho[1-(1-\kappa)(1-b)]\left[b \alpha\left(1-\rho^{2}\right)+1\right]}{(1-\rho)+\rho(1-\kappa)(1-b)}}{2(1-\kappa)(1-b)-(1-\kappa)^{2}(1-b)^{2}} \\
\frac{\operatorname{Var}\left(\Delta s_{t}\right)}{\operatorname{Var}\left(x_{t}\right)}= & \frac{2\left[1+\left(b^{2} \alpha^{2}+2 b \alpha\right)\left(1-\rho^{2}\right)\right]}{[2-(1-\kappa)(1-b)]}- \\
& \frac{2(1-\kappa)(1-b) \rho\left[1+b \alpha\left(1-\rho^{2}\right)\right]}{[2-(1-\kappa)(1-b)][(1-\rho)+\rho(1-\kappa)(1-b)]}
\end{aligned}
$$




$$
\begin{aligned}
& \operatorname{Corr}\left(s_{t}, s_{t-1}\right)=[1-(1-\kappa)(1-b)]+ \\
& \frac{\rho\left[1+b \alpha\left(1-\rho^{2}\right)\right]}{[(1-\rho)+\rho(1-\kappa)(1-b)]} \frac{\operatorname{Var}\left(x_{t}\right)}{\operatorname{Var}\left(s_{t}\right)} \\
& \begin{aligned}
\frac{\operatorname{Cov}\left(\Delta s_{t+1}, i_{t}-i_{t}^{*}\right)}{\operatorname{Var}\left(s_{t}\right)}=-\frac{(1-\kappa)(1-b)^{2}}{b}\left[1-\kappa \operatorname{Corr}\left(s_{t}, s_{t-1}\right)\right]+ \\
\left.\qquad \frac{(1-b)[\rho(1-\rho \kappa)+(1-\kappa)]\left[b \alpha\left(1-\rho^{2}\right)+1\right]}{b[(1-\rho)+\rho(1-\kappa)(1-b)]}-\frac{\rho}{b}\right\} \frac{\operatorname{Var}\left(x_{t}\right)}{\operatorname{Var}\left(s_{t}\right)}, \\
\frac{\operatorname{Var}\left(i_{t}-i_{t}^{*}\right)}{\operatorname{Var}\left(s_{t}\right)}=\frac{(1-b)^{2}}{b^{2}}\left[1+\kappa^{2}-2 \kappa \operatorname{Corr}\left(s_{t}, s_{t-1}\right)\right]+ \\
\frac{1}{b^{2}}\left[1-2(1-b)(1-\rho \kappa) \frac{b \alpha\left(1-\rho^{2}\right)+1}{(1-\rho)+\rho(1-\kappa)(1-b)}\right] \frac{\operatorname{Var}\left(x_{t}\right)}{\operatorname{Var}\left(s_{t}\right)},
\end{aligned}
\end{aligned}
$$

where $\alpha=\alpha^{*}=1 /(1-b)$ in equilibrium. 


\section{References}

Adam, K., Evans, G.W., and Honkapohja, S., 2006. Are hyperinflation paths learnable?, Journal of Economic Dynamics and Control 30, 2725-2748.

Amromin, G. and Sharpe, S.A., 2014. From the horse's mouth: economic conditions and investor expectations of risk and return, Management Science 60, 845-866.

Andersen, T.G., Bollerslev, T., Diebold, F.X., and Vega, C., 2003. Micro effects of macro announcements: real-time price discovery in foreign exchange, American Economic Review 93, 38-62.

Bacchetta, P. and Van Wincoop, E., 2004. A scapegoat model of exchange rate fluctuations, American Economic Review, Papers and Proceedings 94, 114-118.

Bacchetta, P. and Van Wincoop, E., 2007. Random walk expectations and the forward discount puzzle, American Economic Review, Papers and Proceedings 97, 346-350.

Bacchetta, P. and Van Wincoop, E., 2013. On the unstable relationship between exchange rates and macroeconomic fundamentals, Journal of International Economics 91, 18-26.

Baillie, R. and Chang, S., 2011. Carry trades, momentum Trading and the forward premium anomaly, Journal of Financial Markets 14, 441-464.

Baillie, R. and Cho, D., 2014. Time variation in the standard forward premium regression: some new models and tests, Journal of Empirical Finance 29, 52-63.

Balke, N., Ma, J., and Wohar, M., 2013. The contribution of economic fundamentals to movements in exchange rates, Journal of International Economics 90, 1-16.

Bartolini, L. and Giorgianni, L., 2001. Excess volatility of exchange rates with unobservable fundamentals, Review of International Economics 9, 518-530.

Blanchard, O.J. and Kahn, C.M., 1980. The solution of linear difference models under rational expectations, Econometrica 48, 1305-1311.

Burnside, C., 2011. The cross section of foreign currency risk premia and consumption growth risk: comment, American Economic Review 101, 3456-3476.

Burnside, C., Eichenbaum, M., and Rebelo, S., 2011. Carry trade and momentum in currency markets, Annual Review of Finance and Economics 3, 511-535.

Burnside, C., Han, B., Hirshleifer, D., and Wang, T.Y., 2011. Investor overconfidence and the forward premium puzzle, Review of Economic Studies 78, 523-558.

Bansal, R., 1997. An exploration of the forward premium puzzle in currency markets, Review of Financial Studies 10, 369-403.

Branch, W.A. and McGough, B., 2005. Consistent expectations and misspecification in stochastic non-linear economies, Journal of Economic Dynamics and Control 29, 659-676.

Campbell, J. and Cochrane, J., 1999. By force of habit: a consumption-based explanation of aggregate stock market behavior, Journal of Political Economy 107, 205-251.

Chakraborty, A. and Evans, G.W., 2008. Can perpetual learning explain the forward-premium puzzle?, Journal of Monetary Economics 55, 477-490.

Cheung, Y-W., Chinn, M. D., and Pascual, A. G., 2005. Empirical exchange rate models of the nineties: are any fit to survive?, Journal of International Money and Finance 24, 1150-1175.

Chinn, M., 2006. The (partial) rehabilitation of interest rate parity in the floating rate era: longer horizons, alternative explanations, and emerging markets, Journal of International Money and Finance 25, 7-21.

Cochrane, J.H., 1991. A critique of the application of unit root tests, Journal of Economic Dynamics and Control 15, 275-284.

Coibion, O. and Gorodnichenko, Y., 2015. Information rigidity and the expectations formation process: a Simple framework and new facts, American Economic Review 105, 2644-2678 
Dick, C.D. and Menkhoff, L., 2013. Exchange rate expectations of chartists and fundamentalists, Journal of Economic Dynamics and Control 37, 1362-1383.

Ding, L. and Ma, J., 2013. Portfolio reallocation and exchange rate dynamics, Journal of Banking and Finance 37, 3100-3124.

Engel, C., 1996. The forward discount anomaly and the risk premium: a survey of recent evidence, Journal of Empirical Finance 3, 123-191.

Engel, C., 2014. Exchange rates and interest parity, in G. Gopinath, E. Helpman, and K. Rogoff, (eds.), Handbook of International Economics Volume 4. Amsterdam: Elsevier, pp. 453-516.

Engel, C. and West, K., 2005. Exchange rates and fundamentals, Journal of Political Economy 113, 485-517.

Engel, C. and West, K., 2006. Taylor rules and the Deutschmark-Dollar real exchange rate, Journal of Money, Credit, and Banking 38, 1175-1194.

Engel, C., Wang, J., and Wu, J., 2010. Long-horizon forecasts of asset prices when the discount factor is close to unity, Working Paper.

Evans, G.W. and Honkapohja, S., 2001. Learning and Expectations in Economics. Princeton: Princeton University Press.

Evans, G.W. and Ramey, G., 2006. Adaptive expectations, underparameterization, and the Lucas critique, Journal of Monetary Economics 53, 249-264.

Fama, E., 1984. Forward and spot exchange rates, Journal of Monetary Economics 14, 319338.

Flood, R.P. and Rose, A.K., 2002. Uncovered interest rate parity in crisis, IMF Staff Papers 49, 252-266.

Froot. K.A. and Thaler, R.H., 1990. Anomalies: foreign exchange, Journal of Economic Perspectives 4(3), 179-192.

Galí, J., Gertler, M., López-Salido, J.D., 2005. Robustness of the estimates of the Hybrid New Keynesian Phillips Curve, Journal of Monetary Economics 52, 1107-1118.

Gourinchas, P.-O. and Tornell, A., 2004. Exchange rate puzzles and distorted beliefs, Journal of International Economics 64, 303-333.

Greenwood, R. and Shleifer, A., 2014. Expectations of returns and expected returns, Review of Financial Studies 27, 714-746.

Huang, R., 1981. The monetary approach to exchange rate in an efficient foreign exchange market: tests based on volatility, Journal of Finance 36, 31-41.

Hommes, C., 2013. Behavioral Rationality and Heterogeneous Expectations in Complex Economic Systems. Cambridge: Cambridge University Press.

Hommes, C. and Sorger, G., 1998. Consistent expectations equilibria, Macroeconomic Dynamics 2, 287-321.

Hommes, C. and Zhu, M., 2014. Behavioral learning equilibria, Journal of Economic Theory $150,778-814$.

Ilut, C., 2012. Ambiguity aversion: implications for the uncovered interest rate parity puzzle, American Economic Journal: Macroeconomics 4, 33-65.

Justiniano, A. and Preston, B., 2010. Monetary policy and uncertainty in an empirical small open-economy model, Journal of Applied Econometrics 23, 93-128.

Ko, H.-H. and Ogaki, M., 2015. Granger causality from exchange rates to fundamentals: what does the bootstrap test show us? International Review of Economics $\mathcal{G}$ Finance 38, 198-206.

Koijen, R.S.J., Schmeling, M, and Vrugt, E.B., 2015. Survey expectations of returns and asset pricing puzzles, Working Paper. 
Mankiw. N.G., and Reis, R., 2002. Sticky information versus sticky prices: a proposal to replace the New Keynesian Phillips Curve, Quarterly Journal of Economics 117, 1295-1328.

Lansing, K.J., 2009. Time-varying U.S. inflation dynamics and the New Keynesian Phillips Curve, Review of Economic Dynamics 12, 304-326.

Lansing, K.J., 2010. Rational and near-rational bubbles without drift, Economic Journal 120, 1149-1174.

Lubik, T.A. and Schorfheide, F., 2007. Do central banks respond to exchange rate movements? A structural investigation. Journal of Monetary Economics 54, 1069-1087.

Lustig, H. and Verdelhan, A., 2007. The cross section of foreign currency risk premia and consumption growth risk, American Economic Review 97, 89-117.

Lustig, H., Roussanov, N., and Verdelhan, A., 2014. Countercyclical currency risk premia, Journal of Financial Economics.111, 527-553

Mark, N., 2009. Changing monetary policy rules, learning, and real exchange rate dynamics, Journal of Money, Credit, and Banking 41, 1047-1070.

Meese, R. A., and Rogoff, K., 1983. Empirical exchange rate models of the seventies: do they fit out of sample? Journal of International Economics 14, 3-24.

Nerlove, M., 1967. Distributed lags and unobserved components in economic time series, in W. Fellner, (ed.), Ten Economic Studies in the Tradition of Irving Fischer. New York: John Wiley \& Sons, pp. 127-169.

Rossi, B., 2013. Exchange rate predictability, Journal of Economic Literature 51, 1063-1119.

Sarno, L., 2005. Viewpoint: towards a solution to the puzzles in exchange rate economics: where do we stand? Canadian Journal of Economics 38, 673-708.

Sögner, L. and Mitlöhner, H., 2002. Consistent expectations equilibria and learning in a stock market, Journal of Economic Dynamics and Control 24, 799-831.

Ter Ellen, S., Verschoor, W.F.C., and Zwinkels, R.C.J., 2013. Dynamic expectation formation in the foreign exchange market, Journal of International Money and Finance 37, 75-97.

Verdelhan, A., 2010. A habit-based explanation of the exchange rate risk premium, Journal of Finance 65, 123-145.

Wadhwani, S.B., 1987. Are exchange rates "excessively" volatile? Journal of International Economics 22, 339-348.

West, K., 1987. A standard monetary model and the variability of the Deutschemark-Dollar exchange rate, Journal of International Economics 23, 57-76.

$\mathrm{Yu}$, J., 2013. A sentiment-based explanation for the forward premium puzzle, Journal of Monetary Economics 60, 474-491. 